\title{
Patients immunodéprimés, quel pathogène pour quel déficit immunitaire ? (en dehors de l'infection à VIH)
}

\section{Immunocompromised patients with lung infection: assessing host specificities}

\author{
G. Dumas $\cdot$ N. Bigé $\cdot$ V. Lemiale $\cdot$ E. Azoulay \\ Reçu le 13 mars 2018; accepté le 21 juin 2018 \\ (C) SRLF et Lavoisier SAS 2018
}

\begin{abstract}
Résumé Le nombre de patients immunodéprimés ne cesse d'augmenter en raison de l'amélioration du pronostic global du cancer et de l'utilisation croissante d'immunosuppresseurs tant en transplantation qu'au cours des maladies autoimmunes. Les infections sévères restent la première cause d'admission en réanimation dans cette population et sont dominées par les atteintes respiratoires. On distingue les déficits primitifs, volontiers révélés dans l'enfance, des déficits secondaires (médicamenteux ou non), les plus fréquents. Dans tous les cas, les sujets sont exposés à des infections inhabituelles de par leur fréquence, leur type et leur sévérité. À côté des pyogènes habituels, les infections opportunistes et la réactivation d'infections latentes font toute la complexité de la démarche diagnostique. Celle-ci doit être rigoureuse, orientée par le type de déficit, les antécédents, les prophylaxies éventuelles et la présentation clinicoradiologique. Elle permettra seule de guider le traitement probabiliste et les examens étiologiques, l'absence de diagnostic étant associée à une mortalité élevée.
\end{abstract}

Mots clés Immunodéprimé $\cdot$ Insuffisance respiratoire aiguë - Pneumonie

\begin{abstract}
The number of patients living with immune deficiency has been dramatically increased. Nevertheless, these patients may experience several life-threatening complications warranting admission to the intensive care unit. Respiratory infection remains the leading cause of admission with high reported mortality rates. One could distinguish primary and secondary immunodeficiency disorders. Secondary
\end{abstract}

\footnotetext{
G. Dumas · N. Bigé

Service de réanimation médicale, hôpital Saint-Antoine,

184, rue du Faubourg-Saint-Antoine, F-75012 Paris, France

V. Lemiale $\cdot$ E. Azoulay $(\bowtie)$

Service de réanimation médicale, hôpital Saint-Louis, AP-HP,

1, avenue Claude-Vellefaux, F-75010 Paris, France

e-mail : elie.azoulay@aphp.fr
}

immunodeficiency disorders are the most frequent ones with the development of new treatments such as targeted therapies. Various infectious disorders may occur with special attention for opportunistic pathogens and latent infection reactivation. Diagnostic strategy gets leading by immunodeficiency condition, prophylaxis, clinical presentation, and radiologic pattern. This drives choices in empiric treatment and diagnosis tools. Physicians must bear in mind that failure to identify the etiology of pulmonary involvement is associated with higher mortality.

Keywords Immunocompromised · Acute respiratory failure $\cdot$ Pneumonia

\section{Introduction}

Au cours des 25 dernières années, le nombre de patients vivants avec une immunodépression n'a cessé d'augmenter [1]. Bien que le pronostic de ces patients se soit amélioré [2], ils restent exposés à un risque élevé de complications pouvant mettre en jeu le pronostic vital. L'insuffisance respiratoire aiguë demeure le principal motif d'admission en réanimation [3-5] avec une mortalité élevée, jusqu'à $60 \%$ des cas selon les situations [6]. L'absence de diagnostic étiologique reste un marqueur péjoratif fort [7], soulignant la nécessité pour le clinicien d'adopter une démarche rigoureuse, orientée par les conditions d'immunodépression et la présentation clinique, souvent trompeuse [8]. En effet, l'altération des défenses immunitaires, qu'elle soit le fait de la pathologie sous-jacente et/ou des traitements reçus, expose à un risque infectieux accru, dont la fréquence et les caractéristiques peuvent varier en fonction du mécanisme sous-jacent [9]. Si les risques bactérien et viral restent au premier plan, l'immunodépression favorise l'émergence d'infections opportunistes et la réactivation d'infections latentes, dont le tropisme respiratoire est fréquent [10]. 
L'objectif de cette revue est de présenter les principales complications infectieuses respiratoires rencontrées chez le patient immunodéprimé, en insistant sur celles susceptibles d'être rencontrées en réanimation.

\section{Principaux types d'immunosuppression}

Le terme de déficit immunitaire regroupe un ensemble hétérogène de pathologies affectant le système immunitaire, à l'origine d'infections inhabituelles par leur fréquence, leur sévérité ou la nature de l'agent infectieux en cause (pathogène opportuniste). Le système immunitaire ayant un rôle majeur dans l'homéostasie de l'organisme, des complications telles que la survenue de tumeurs ou de pathologies auto-immunes ne sont pas rares [11], expliquant par ailleurs l'intérêt grandissant en thérapeutique du blocage de ses effecteurs [12].

On distingue schématiquement les systèmes immunitaires inné et adaptatif, chacun composé d'une phase humorale et d'une phase cellulaire. Le système immunitaire inné permet une réponse rapide aux infections. Ces composants cellulaires principaux sont les cellules phagocytaires (cellules dendritiques, macrophages et polynucléaires neutrophiles, $\mathrm{PNN}$ ), les lymphocytes natural killer (NK), permettant une destruction directe des cellules infectées, et sa phase humorale repose principalement sur le système du complément [13]. Le système immunitaire adaptatif est constitué des lymphocytes $\mathrm{T}$ et $\mathrm{B}$ (phase cellulaire) ainsi que des anticorps (phase humorale) [11].

Chacune de ces composantes peut être affectée par un phénomène pathologique ou un blocage médicamenteux. Il est habituel de séparer les déficits immunitaires primitifs (d'origine génétique), classiquement découverts dès l'enfance mais pouvant se révéler à l'âge adulte, des déficits immunitaires secondaires, les plus fréquents [14]. Ces déficits peuvent toucher l'ensemble d'un système de défense (cas des chimiothérapies) ou cibler une voie spécifique (cas des anticorps monoclonaux). Cette distinction est cependant rendue complexe par l'intrication des différentes voies du système immunitaire et l'association fréquente chez un même patient de plusieurs causes d'immunodépression (cas de l'allogreffe de moelle osseuse ou des traitements immunosuppresseurs [IS]). Le tableau 1 présente les principaux déficits immunitaires et les agents infectieux incriminés.

\section{Infections associées à une atteinte de l'immunité humorale}

Elles sont représentées en pratique courante par l'hypogammaglobulinémie, les déficits dans la voie du complément et l'asplénie.

\section{Hypogammaglobulinémie}

Les immunoglobulines (Ig) ont un rôle majeur dans l'immunité anti-infectieuse via trois sous-classes principales (IgG, IgA, IgM), dont les actions se placent à plusieurs niveaux [15] :

- bactéricidie envers les bactéries à Gram négatif (Neisseria principalement);

- opsonisation des bactéries pour en faciliter l'élimination lors de la phagocytose. Il s'agit principalement des bactéries extracellulaires, à croissance rapide (cocci à Gram positif et entérobactéries) ;

- neutralisation des toxines bactériennes (exemple : tétanos ou diphtérie).

Les hypogammaglobulinémies se définissent par une diminution du taux de gammaglobulines $(<5 \mathrm{~g} / \mathrm{l})$ sur l'électrophorèse des protéines, confirmée par un dosage pondéral des différentes sous-classes. La profondeur du déficit est variable et peut concerner l'ensemble des Ig ou des sousclasses particulières (déficits sélectifs en IgG ou IgA).

Les formes congénitales telles que l'agammaglobulinémie de Bruton (mutation du gène de la Bruton's tyrosine kinase lié à l'X, responsable d'une absence de lymphocytes B) sont généralement révélées dès l'enfance par des infections récidivantes, notamment respiratoires [16]. Une découverte à l'âge adulte n'est pas rare, en particulier pour le déficit immunitaire commun variable (DICV), qui représente le déficit immunitaire symptomatique le plus fréquent, avec une prévalence estimée à $1 / 20000$, et dont le diagnostic est habituellement porté dans les deuxième ou troisième décennies [17].

Les formes secondaires, de loin les plus fréquemment rencontrées à l'âge adulte, viennent compliquer trois situations cliniques [18] :

- les hémopathies lymphoïdes (LLC, myélome, lymphomes non hodgkiniens, maladie de Waldenström), qui peuvent être révélées à l'occasion d'une complication infectieuse ;

- un excès de pertes (syndrome néphrotique, entéropathies exsudatives, pertes cutanées lors de brûlures ou dermatoses étendues) ;

- la prise de certains médicaments (corticothérapie prolongée, chimiothérapie, carbamazépine, sels d'or, antipaludéens de synthèse).

Le rituximab, anticorps monoclonal anti-CD20 ciblant le lymphocyte B, utilisé dans le traitement des lymphomes non hodgkiniens, mais aussi d'un grand nombre de maladies auto-immunes, peut être responsable d'une hypogammaglobulinémie chez 5 à $40 \%$ des patients selon la pathologie sous-jacente [19], cependant peu symptomatique bien que le taux d'Ig résiduel soit corrélé au risque infectieux [20]. 
Tableau 1 Principaux déficits immunitaires et agents infectieux fréquemment incriminés

\begin{tabular}{|c|c|}
\hline Mécanisme & Pathologies sous-jacentes \\
\hline \multicolumn{2}{|c|}{ Déficit de l'immunité humorale } \\
\hline $\begin{array}{l}\text { Hypogammaglobuliné- } \\
\text { mie }\end{array}$ & $\begin{array}{l}\text { Primitive : maladie de Bruton (liée à l'X), DICV, } \\
\text { déficits sélectifs en IgG ou en IgA } \\
\text { Secondaire : myélome, maladie de Waldenström, } \\
\text { leucémie lymphoïde chronique, lymphome non } \\
\text { hodgkinien, thymome (syndrome de Good), } \\
\text { chimiothérapie, biothérapie (rituximab), syndrome } \\
\text { néphrotique, entéropathie exsudative }\end{array}$ \\
\hline Déficit du complément & $\begin{array}{l}\text { Congénital (C2, C3, C4, complexe d'attaque } \\
\text { membranaire, facteur I, H, MBL, voies des lectines) } \\
\text { Secondaire : lupus, médicamenteux (éculizumab) }\end{array}$ \\
\hline Asplénie et hyposplénie & $\begin{array}{l}\text { Anatomique (splénectomie congénitale) } \\
\text { Fonctionnelle : irradiation corporelle totale, } \\
\text { drépanocytose, allogreffe de moelle osseuse, } \\
\text { maladie cœliaque, MICI, lupus, polyarthrite } \\
\text { rhumatoïde, thrombose des vaisseaux spléniques, } \\
\text { amylose }\end{array}$ \\
\hline
\end{tabular}

Altération de la phagocytose

Neutropénie Hémopathies malignes : leucémies aiguës, syndromes myélodysplasiques

Agents pathogènes les plus fréquents

$\begin{array}{ll} & \begin{array}{l}\text { syndromes myélodysplasiques } \\ \text { Hémopathie non maligne : aplasie médullaire } \\ \text { idiopathique ou secondaire } \\ \text { Médicamenteuse : chimiothérapie, radiothérapie, } \\ \text { immunoallergique }\end{array} \\ \text { Anomalies } & \text { Neutropénies congénitales ou auto-immunes } \\ \text { fonctionnelles des PNN, } & \text { Granulomatose chronique familiale } \\ \text { monocytes } & \text { Médicamenteuses : chimiothérapie, radiothérapie, } \\ \text { et macrophages } & \text { corticothérapie } \\ & \text { Hémopathies : LMC, leucémies aiguës }\end{array}$

\section{Déficit de l'immunité cellulaire}

Lymphopénie $\mathrm{T}$

Dysfonction

Infection par le VIH (CD4+)

lymphocytaire

Immunosuppresseurs, anticorps anti-TNF

Corticothérapie

Maladies auto-immunes : lupus, vascularites

Hémopathies malignes : lymphome hodgkinien

ou non hodgkinien, leucémies

Post-transplantation : organes solides, moelle

osseuse

Congénitaux : DICS, syndrome de Di George,

syndrome de Wiskott-Aldrich, Ataxie-télangiectasie

Lymphopénie CD4+ idiopathique
Bactéries : encapsulées (pneumocoque, méningocoque, Haemophilus influenzae),

Mycoplasma pneumoniae

Virus : VRS, Influenzae, Parainfluenzae
Courte durée $(<10$ jours $)$

Bactéries :

à Gram négatif : entérobactéries,

Pseudomonas aeruginosa

à Gram positif : Staphylocoque, Streptocoque,

Entérocoque

Prolongée :

Champignons : Aspergillus, Candida (localisation

secondaire++), mycoses émergentes

(Trichosporosis, Fusarioses, Zygomycète,

Scedosporium)

Virus : herpès virus

Bactéries :

Pneumocoque, Légionnelle, Mycoplasme, Nocardia, mycobactéries (complexes tuberculosis et atypiques)

Champignons :

Pneumocystose, aspergillose, mycoses

endémiques : cryptococcose, histoplasmose,

blastomycoses Coccidioïdomycose

Parasites : toxoplasmose

Virus : CMV, VZV, VRS, Parainfluenzae, adénovirus

LMC : leucémie myéloïde chronique ; DICV : déficit immunitaire commun variable ; DICS : déficit immunitaire combiné sévère ; VIH : virus de l'immunodéficience humaine ; CMV : cytomégalovirus ; VZV : varicelle zona virus ; HSV : herpès simplex virus ; VRS : virus respiratoire syncytial 
Enfin, au cours de l'allogreffe de moelle osseuse, une hypogammaglobulinémie n'est pas rare y compris de façon prolongée traduisant un défaut de reconstitution du répertoire B [21].

Quelle que soit sa cause (congénitale ou acquise), l'hypogammaglobulinémie expose à la survenue d'infections répétées et parfois sévères à des bactéries à croissance extracellulaire, habituellement encapsulées, telles que Streptococcus pneumoniae ou Haemophilus influenzae. L'ensemble des bactéries des groupes Streptococcus, Staphylococcus ou des entérobactéries sont plus largement impliquées. Les voies aériennes hautes et basses sont les localisations infectieuses principales [22]. Du fait de la répétions des épisodes infectieux et parfois de la survenue d'une dilatation des bronches, la possibilité d'une colonisation à Pseudomonas aeruginosa ou à Staphylococcus aureus n'est pas rare [23].

Un cas particulier est représenté par le syndrome de Good, dont le diagnostic est généralement porté entre la quatrième et la cinquième décennie et qui associe une agammaglobulinémie et un thymome [18]. Les complications infectieuses sont fréquentes et variées, associant à la fois des bactéries encapsulées mais aussi des infections répétées à germes intracellulaires (CMV, HSV mais aussi Cryptosoridium, Toxoplasma, Pneumocystis ou Candida). Au plan biologique, outre la lymphopénie B, une hyperlymphocytose TCD8+, une neutropénie ou une érythroblastopénie sont fréquemment associées [24].

La prise en charge repose essentiellement sur la supplémentation en Ig polyvalentes par voie intraveineuse ou souscutanée qui permet une diminution de la fréquence des infections. Toujours indiquée dans les formes congénitales, elle est recommandée chez les patients présentant une forme acquise, en cas d'infections répétées [25].

\section{Déficits du système du complément}

Le système du complément est un acteur majeur de l'immunité innée. Outre son rôle dans la destruction directe des pathogènes via le complexe d'attaque membranaire, le complément permet l'opsonisation des bactéries encapsulées et facilite leur phagocytose (fragment $\mathrm{C} 3 \mathrm{~b}$ ), exerce une action de chimiotactisme pour les polynucléaires (C5a), participe à la clairance des complexes immuns circulants et à la réponse anticorps-dépendante [26]. Le risque infectieux associé au déficit en protéine du complément dépend de sa cause (acquise ou congénitale) et de la fraction déficitaire [27].

Les déficits congénitaux en protéines du complément sont extrêmement rares $(0,03 \%$ de la population générale). Les déficits en facteurs de la voie finale commune (C5-C9) exposent principalement à un risque accru d'infection à Neisseria meningitidis. Les déficits en facteur $\mathrm{C} 3$ (héréditaires ou acquis, liés à la présence d'autoanticorps) exposent à un risque majeur d'infection récidivante à germes encapsulés (S. pneumoniae et $N$. meningitidis), de même que les déficits en facteurs $\mathrm{H}$ et $\mathrm{I}$, impliqués dans la régulation de la voie alterne, ou que les déficits en protéines de la voie classique (C1q, C2, C4) [28]. Au cours des formes acquises (lupus, syndrome néphrotique), le risque infectieux lié au déficit reste mal établi, en dehors du traitement par éculizumab (anticorps monoclonal ciblant la fraction C5) utilisé principalement dans le traitement des syndromes hémolytiques et urémiques atypiques et de l'hémoglobinurie paroxystique nocturne [29].

\section{Asplénie et hyposplénisme}

La rate est un organe lymphoïde branché sur la circulation splanchnique qui joue un rôle crucial dans l'homéostasie du système immunitaire, en particulier par son action de « filtre phagocytaire » et la production rapide d'anticorps spécifique [30]. C'est en effet dans la zone marginale splénique qu'est retrouvée la grande majorité des lymphocytes B mémoire de type IgM, seuls capables de produire de façon rapide et spécifique des anticorps naturels dirigés contre les bactéries encapsulées, permettant leur élimination dans les premières heures de la réponse anti-infectieuse [31]. L'asplénie est définie par l'absence de rate (le plus souvent postchirurgicale) et se distingue de l'hyposplénisme ou asplénie fonctionnelle, qui correspond à une diminution des fonctions spléniques, observée dans un grand nombre de pathologies (Tableau 1).

Le diagnostic peut être facilement suspecté sur la clinique, la présence de corps de Jolly au frottis sanguin ou de façon plus précise par méthode isotopique [30].

Dès les années 1950, il fut reconnu que l'atteinte des fonctions splénique expose à un risque infectieux majeur aux germes encapsulés principalement ( $S$. pneumoniae, $H$. influenzae et $N$. meningitidis) sous forme d'infection fulminante le plus souvent [32] et volontiers à point de départ pulmonaire [33]. Ce risque de pneumonie est augmenté dès la période postopératoire. Ainsi, dans une série portant sur 15411 patients ayant subi une splénectomie d'hémostase, Fair et al. [34] retrouvaient un risque de pneumonie postopératoire significativement augmenté (OR : 1,41 ; IC $95 \%$ : [1,26-1,57], $p<0,001)$. Ce risque infectieux persiste à long terme. Dans une étude parue en 2014 chez 52 patients aspléniques pris en charge pour un sepsis fulminant, Theilacker et al. [35] retrouvaient un délai médian de survenue de l'épisode de six ans après la splénectomie. Dans ce même travail, $S$. pneumoniae était le germe le plus fréquemment identifié ( $42 \%$ des patients), et la pneumonie était le site infectieux le plus souvent retrouvé (40\%).

Le diagnostic étiologique ne pose généralement pas de problème dans cette population, et la sévérité clinique impose l'administration d'une antibiothérapie ciblant le pneumocoque sans attendre le plus souvent la réalisation d'exploration microbiologique respiratoire $[32,35]$. 


\section{Infections associées à une atteinte des polynucléaires neutrophiles ou de la phagocytose}

La phase cellulaire de l'immunité innée repose sur des cellules ayant développé la capacité de phagocyter les microorganismes, mais aussi de libérer de nombreuses cytokines pro-inflammatoires (exemple : TNF-alpha, interleukine [IL] 1-6) ainsi que des chémokines (exemple : IL-8) capables d'exercer un chimiotactisme d'autres cellules de l'inflammation dans la région agressée. Cette phagocytose peut être réalisée de façon directe après contact avec l'agent infectieux ou indirectement après opsonisation de celui-ci [36]. Cette phagocytose est ensuite suivie d'une microbicidie résultant entre autres de l'activité oxydative conduite par la myéloperoxydase intragranulocytaire [36]. Par ailleurs, les cellules macrophagiques assurent un dialogue avec l'immunité adaptative grâce à leur capacité de présentation de l'antigène et jouent un rôle majeur dans les réactions d'hypersensibilité retardée conduisant en particulier à la formation des granulomes [37].

Un déficit quantitatif ou qualitatif des PNN ou des cellules mononucléées expose ainsi à un risque bactérien mais aussi fongique. Le risque d'infections virales ou parasitaires n'est généralement pas augmenté.

\section{Neutropénie}

La neutropénie se définit par une diminution du nombre absolu de PNN circulants. Elle peut être minime (1 000 et $1500 / \mathrm{mm}^{3}$ ), modérée (entre 500 et $1000 / \mathrm{mm}$ ) ou sévère $\left(<500 / \mathrm{mm}^{3}\right)$. Le risque infectieux associé est variable. Il dépend de la profondeur de la neutropénie, du mécanisme périphérique ou central (plus élevé dans ce cas), de sa durée ( $>7$ jours), mais aussi du chiffre des monocytes et des autres immunosuppressions associées (IS, hypogammaglobulinémie...) [38].

La grande majorité des neutropénies est acquise, liée à une toxicité médullaire directe des traitements. La plupart des chimiothérapies utilisées pour les tumeurs solides et pour le traitement conventionnel des hémopathies lymphoïdes ou myéloïdes exposent à des neutropénies de durée inférieure à sept jours et de profondeur variable selon la molécule, habituellement prévenue par l'administration de facteurs de croissance (G-CSF). En revanche, lors des phases d'induction de leucémie aiguë ou lors du conditionnement des auto/allogreffes, le nadir de PNN atteint généralement $0 / \mathrm{mm}^{3}$, avec une durée supérieure à dix jours. D'autres traitements peuvent être impliqués avec un mécanisme toxique (antithyroïdien de synthèse, colchicine) ou immunologique (phénytoine), en conditionnant la durée et la sévérité. Les autres causes de neutropénies acquises sont dominées par l'envahissement médullaire d'une hémopathie ou d'une tumeur solide, une origine infectieuse (virale en particulier) ou une cause auto-immune (primitive ou secondaire comme au cours du lupus). Un cas particulier est la neutropénie des syndromes myélodysplasiques ou de la leucémie à grands lymphocytes granuleux, qui associe souvent un défaut chronique de production (exposant à des durées de neutropénie prolongées) et des anomalies qualitatives altérant les fonctions phagocytaires [38]. Tous ces éléments seront à prendre en compte lors de la démarche diagnostique.

L'atteinte respiratoire reste la première cause de sepsis chez le patient neutropénique [5], et son potentiel évolutif justifie une prise en charge hospitalière $[39,40]$.

À la phase initiale de la neutropénie ou pour les neutropénies de courte durée, les germes les plus fréquemment incriminés en l'absence d'exposition récente aux antibiotiques restent $S$. pneumoniae, $S$. aureus et $H$. influenzae $[40,41]$ en association avec les bacilles à Gram négatif issues de la flore endogène (Klebsiella pneumoniae en particulier). Chez les patients présentant une neutropénie chimio-induite, $P$. aeruginosa reste un germe fréquemment incriminé [41] (jusqu'à $40 \%$ des cas) du fait de la pression de sélection antibiotique, en particulier en cas de neutropénie profonde.

L'utilisation de dispositif intraveineux de longue durée et d'antibiotiques actifs sur les bactéries à Gram négatif a favorisé l'émergence d'infection à $S$. aureus résistants à la méticilline dans cette population. Une mucite liée à la toxicité muqueuse de certaines chimiothérapies (cytarabine par exemple) expose également à la survenue de pneumonie à Streptococcus viridans [42]. Stenotrophomonas maltophilia et les autres bacilles à Gram négatif non fermentant peuvent être à l'origine de pneumonie nosocomiale en particulier chez le patient ventilé.

Le risque d'infection fongique (Aspergillus surtout, mais aussi Mucorales) devient majeur en cas de neutropénies profondes et prolongées [43,44], principalement au cours des chimiothérapies d'induction de leucémie aiguë ou chez le patient allogreffé de moelle osseuse. La présentation clinique est volontiers fruste et se limite le plus souvent à une fièvre persistante malgré une antibiothérapie à large spectre, parfois associée à un infiltrat sur la radiographie thoracique [45]. La réalisation précoce d'un scanner thoracique peut aider à distinguer une origine bactérienne d'une cause fongique et reste l'examen de choix. Une présentation nodulaire ou une cavitation doit faire évoquer une infection à champignon filamenteux [46]. L'aspect scanographique le plus fréquent au cours de l'aspergillose pulmonaire invasive (API) est le macronodule $(>1 \mathrm{~cm})$, volontiers périphérique [47], présent chez $94 \%$ des cas dans une série récente de 235 patients [48]. Ces nodules étaient souvent multiples (79\%) et bilatéraux (60\%). Un signe du Halo, défini par un nodule serti d'une couronne en verre dépoli, est l'élément le plus évocateur qui était retrouvé dans $60 \%$ des cas. D'autres aspects sont possibles tels qu'une consolidation, un aspect d'infarcissement ou une cavitation. 
La présence d'un signe du croissant gazeux est quant à elle quasi pathognomonique, mais tardive [47]. Cette description doit cependant être nuancée :

- les aspects scanographique et clinique restent influencés par le chiffre de PNN circulants : l'aspect d'AP angioinvasive (défini par la présence d'un signe du Halo) est plus fréquemment retrouvé chez les patients avec un taux de PNN inférieur à $100 / \mathrm{mm}^{3}$, tandis que l'aspect bronchoinvasif (aspect de micronodules avec ou sans aspect d'arbre en bourgeon) est l'apanage des patients ayant un taux de PNN supérieur à $100 / \mathrm{mm}^{3}$ [49];

- aucun aspect radiologique n'est entièrement spécifique. Ainsi, un signe du Halo peut s'observer au cours d'autres infections bactérienne ( $P$. aeruginosa) ou fongique (Mucorales, autres champignons opportunistes) ;

- les formes polymicrobiennes ne sont pas rares (environ $15 \%$ des cas) [50].

La distinction avec d'autres infections fongiques reste difficile, en particulier la Mucormycose. Au plan radiologique, les présences de nodules multiples (>10), d'un épanchement pleural, d'un aspect du Halo inversé, d'une atteinte des sinus sont évocatrices, surtout chez un patient évoluant défavorablement sous voriconazole [44,51].

Si le diagnostic de certitude repose sur la mise en évidence de filaments aspergillaires dans une biopsie, celle-ci est rarement réalisée en pratique du fait des troubles de l'hémostase fréquemment associés [45]. Par ailleurs, les filaments aspergillaires ne sont mis en évidence dans le LBA que dans moins d'un tiers des cas. L'apport de la PCR dans cette situation pourrait être utile [52]. Actuellement, la détection de l'antigène aspergillaire dans le sang ou le LBA, dans un contexte évocateur, reste un élément clé pour le diagnostic d'API [45]. Dans le cas de la Mucormycose, l'examen histologique ou mycologique d'un prélèvement respiratoire (invasif ou non) reste la référence. La PCR mucorales semble être un outil prometteur [44]. La fusariose est une autre infection fongique qui connaît une recrudescence ces dernières années en particulier en hématologie. L'aspect clinique et radiologique est peu distinguable de celui de l'API, mais une atteinte cutanée et des sinus est évocatrice. À l'inverse de l'API, le diagnostic est porté par les hémocultures dans $40 \%$ des cas [53].

\section{Déficits fonctionnels des neutrophiles et des phagocytes mononuclés}

On regroupe ici un ensemble de pathologies associant à des degrés divers une anomalie de la bactéricidie intracellulaire ou de la chimiotaxie des PNN. Les causes sont nombreuses, primitives (maladie de Chediak-Higashi ou déficit en myéloperoxydase) ou secondaires (corticothérapie, diabète, chimiothérapie) [18].
La forme la plus sévère et la plus représentative est la granulomatose septique chronique, affection récessive liée à l'X, correspondant à un déficit en NADPH-oxydase, responsable d'une perte de la production des dérivés actifs de l'oxygène (radicaux libres). Il en résulte un défaut de bactéricidie des germes phagocytés. Au plan clinique, se développent des granulomes dans divers organes (tubes digestif), pouvant justifier une corticothérapie majorant le risque infectieux. Les patients présentent essentiellement des infections répétées à bactéries catalase $+(S$. aureus, Salmonella $s p$., Burkholderia $s p$., entérobactéries) et à champignons (Aspergillus sp. et Candida sp.). À l'inverse, il n'existe pas de risque concernant les germes catalase (streptocoque) ou à développement intracellulaire [54].

Une autre situation particulière est représentée par les défauts de l'axe IL-12/interféron-gamma. Ces cytokines ont un rôle majeur dans la défense contre les bactéries intracellulaires (mycobatéries en particulier). Plusieurs déficits ont été décrits et sont associés à des infections sévères et disséminées à mycobactéries (Mycobacterium avium, Mycobacterium fortuitum, Mycobacterium chelonae) [54].

Ces situations rares peuvent néanmoins être diagnostiquées à l'âge adulte et doivent être suspectées devant le caractère inhabituel de la présentation. Au plan thérapeutique, ces particularités rendent nécessaire l'utilisation d'antibiotiques avec bonne diffusion intracellulaire et pour des durées souvent prolongées.

\section{Infections associées à une atteinte de l'immunité cellulaire : atteintes des lymphocytes $T$}

L'atteinte des fonctions lymphocytaires T regroupe un ensemble de pathologies primitives mais surtout secondaires, de plus en plus rencontrées en situations cliniques courantes, initialement avec l'infection à VIH et plus récemment avec l'avènement des IS. Le risque infectieux est dominé par les infections virales (herpès virus principalement) et à germes intracellulaires : parasites (Pneumocystis jiroveci, Toxoplasma gondii), champignons et bactéries intracellulaires (Legionella) [9,12].

\section{Déficits acquis}

\section{Quelques cas particuliers liés aux hémopathies malignes}

En dehors de la neutropénie et d'autres déficits immunitaires liés aux traitements, un certain nombre d'hémopathies peuvent s'associer à une susceptibilité infectieuse propre :

- la leucémie à tricholeucocytes est une hémopathie lymphoïde B chronique, caractérisée par la présence de lymphocytes « chevelus » sur le frottis sanguin, une 
splénomégalie et des cytopénies fréquentes (neutropénie, monocytopénie caractéristique, déficit en lymphocytes T et NK). Ce déficit cellulaire s'associe à un risque majoré d'infection, à germes classiques mais surtout à L. pneumophila et mycobactéries atypiques [55];

- au cours de la LLC, il existe un déficit intriqué de l'immunité humorale (hypogammaglobulinémie) et cellulaire. Cette dernière est particulièrement aggravée par les thérapeutiques telles que l'alemtuzumab (anticorps antiCD-52, pan lymphocytaire) ou les analogues des purines (fludarabine, cladribine, pentostatine), qui exposent à un risque accru d'infection à herpès virus (HSV), de mycobactéries, de champignons (Aspergillus, Candida, Cryptocoque et Pneumocystis jirovecii) $[12,56]$.

\section{Greffe de cellules souches hématopoḯtique}

Les greffes de cellules souches hématopoiétiques (CSH) ont pour objectif le traitement de maladies malignes agressives, plus rarement bénignes (drépanocytose, déficit immunitaire constitutionnel). On distingue :

- les autogreffes, correspondant à un support hématopoïétique autologue à un traitement intensif myéloablatif (MA), appelé conditionnement, ayant pour objectif la rémission de la maladie sous-jacente ;

- les allogreffes, correspondant au remplacement du système hématopoiétique défaillant et dont l'action antitumorale résulte de la chimiothérapie intensive précédant la greffe (conditionnement) et de l'effet graftversus-leukemia (GVL) dû aux cellules immunocompétentes du greffon. Plusieurs sources de greffons sont possibles : géno-identique à partir de donneur intrafamilial, phéno-identique à partir d'un donneur sur fichier et, en l'absence totale de donneur HLA compatible, l'utilisation de sang placentaire ou d'un donneur semi-compatible dite greffe haplo-identique. De même, on distingue schématiquement deux types de conditionnements : MA, entrânant la destruction de la moelle osseuse du receveur et non MA ou atténués (NMA) permettant de réduire la morbimortalité, notamment infectieuse. Ce type de greffe expose à un risque de réaction du greffon contre l'hôte ou graft-versus-host $(\mathrm{GVH})$, aiguë ou chronique, nécessitant l'utilisation d'IS majorant le risque infectieux.

$\mathrm{Au}$ cours de l'autogreffe de CSH, le risque infectieux est dominé par la neutropénie faisant suite au conditionnement, dont la durée moyenne est de 11 à 14 jours, ainsi qu'à l'hémopathie sous-jacente et aux traitements préalablement reçus [57]. Sur une étude de cohorte européenne menée sur 38 mois, ayant suivi 726 patients [58], la pneumonie était la deuxième cause de sepsis après les bactériémies isolées, avec un taux d'attaque de 5,4 épisodes pour 100 patients.
Les germes ne diffèrent pas de ceux précédemment décrits, dominés par les bacilles à Gram négatif dont $P$. aeruginosa, les cocci à Gram positif secondaire à la mucite et aux infections de cathéter ainsi que les localisations secondaires d'une candidémie. En pratique, le choix des traitements probabilistes suit les recommandations de toute neutropénie fébrile.

Le risque aspergillaire reste faible dans cette population, mais pourrait augmenter en cas d'utilisation antérieure de thérapies ciblées et de chimiothérapies fortement immunosuppressives comme les analogues des purines [59]. Les complications infectieuses tardives sont rares, la majorité des patients ayant une immunité reconstituée dans l'année suivant l'autogreffe de CSH [57].

Les complications infectieuses sont un facteur de risque majeur de mortalité au cours de l'allogreffe de CSH. L'ensemble des patients allogreffés expérimente une immunodépression profonde et prolongée intéressant à la fois l'immunité cellulaire et humorale [57]. Ce risque varie en fréquence et en nature selon plusieurs facteurs : le délai depuis la greffe, les antécédents infectieux du patient et le statut de la maladie sous-jacente (stade d'évolution, traitements antérieurs), les caractéristiques du greffon (sang de cordon, donneur non apparenté à risque plus élevé), l'utilisation d'IS (corticoïdes, sérum antilymphocytaire) et le conditionnement (réduction de la durée de neutropénie et $\mathrm{du}$ risque infectieux sur les trois premiers mois avec les NMA) [57]. La survenue d'une GVH aiguë est un facteur de risque largement reconnu, exposant à un risque d'infection jusqu'à $60 \%$ plus élevé par rapport aux patients indemnes [60], à la fois bactérien mais également fongique (API) ou viral (CMV) $[60,61]$.

Ce risque infectieux varie en nature avec les différents temps de la reconstitution du système immunitaire. Précoce pour le PNN (trois semaines pour les MA, $<14$ jours pour les NMA) et les lymphocytes NK ou CD8+, la reconstitution d'une immunité humorale complète est beaucoup plus tardive, et la majorité des patients conserve une altération des fonctions immunitaires jusqu'à deux ans après la greffe [57].

Schématiquement, ce risque évolue en trois étapes (Fig. 1) :

- phase précoce (avant la prise de greffe) : elle correspond à la phase de neutropénie profonde et expose aux complications déjà décrite, avec une prédominance d'infections respiratoires bactérienne et fongique ;

- phase postprise de greffe précoce : les infections opportunistes prédominent, liées à l'altération de l'immunité cellulaire, favorisées par la GVH et les traitements IS. Le risque principal est l'infection à CMV [62]. Les autres pathogènes fréquemment incriminés sont la pneumocystose [63] et l'aspergillose [45,49];

- phase tardive ( $>\mathrm{j} 100)$ : le CMV, le VZV et les germes encapsulés sont les agents pathogènes les plus fréquemment 
incriminés. Le risque infectieux est majoré ici en cas de survenue d'une GVH aiguë ou chronique et de sa sévérité, ainsi que chez les patients ayant reçu un greffon de donneur non apparenté [57]. En cas de GVH et de poursuite des IS, la pneumocystose (en l'absence de prophylaxie) et l'API restent d'actualité.

La pneumonie à CMV est suspectée devant une atteinte respiratoire, des images en verre dépoli bilatérales, des opacités alvéolaires et/ou des nodules centrolobulaires au scanner thoracique. Elle est confirmée par la positivité de la PCR dans le sang et le cas échéant dans les prélèvements respiratoires (LBA) [62]. Son incidence a largement diminué depuis la mise en place d'une prophylaxie chez les patients à haut risque et avec les stratégies préemptives. Elle est estimée à 5-8\% des receveurs de CSH [64], et la mortalité reste élevée de l'ordre de 30 à $55 \%$ à six mois. Elle survient majoritairement au cours des 100 premiers jours postgreffe. Les formes tardives sont possibles chez les patients ayant déjà fait une réactivation $\mathrm{CMV}$ précoce, une $\mathrm{GVH}$, une lym- phopénie persistante après $\mathrm{j} 100$ et chez les sujets séropositifs ayant reçu un greffon de donneur séronégatif [65]. Le traitement repose sur le ganciclovir par voie intraveineuse, dont la toxicité médullaire peut être limitante. En deuxième intention, le foscarnet peut être utile, mais expose à un risque élevé de néphrotoxicité [66].

Les infections fongiques invasives représentent un risque majeur, avec une incidence difficile à évaluer, aux alentours de 5 à $9 \%$ [57,67]. L'API est la situation la plus fréquente devant les candidoses invasives, les zygomycoses et la fusariose. L'âge, une mucite grave, une colonisation digestive connue, la durée de la neutropénie, le type de greffon (donneur non apparenté et sang de cordon) ainsi que la GVH aiguë ou chronique sont les facteurs de risque les plus souvent retrouvés [67]. L'utilisation de posaconazole en prophylaxie des infections à Candida et Aspergillus sp. (jusqu'à la sortie d'aplasie ou l'arrêt des IS) a permis une diminution de l'incidence de ces infections [68]. Cependant, sa biodisponibilité orale est largement altérée en cas de troubles digestifs (mucite, GVH).

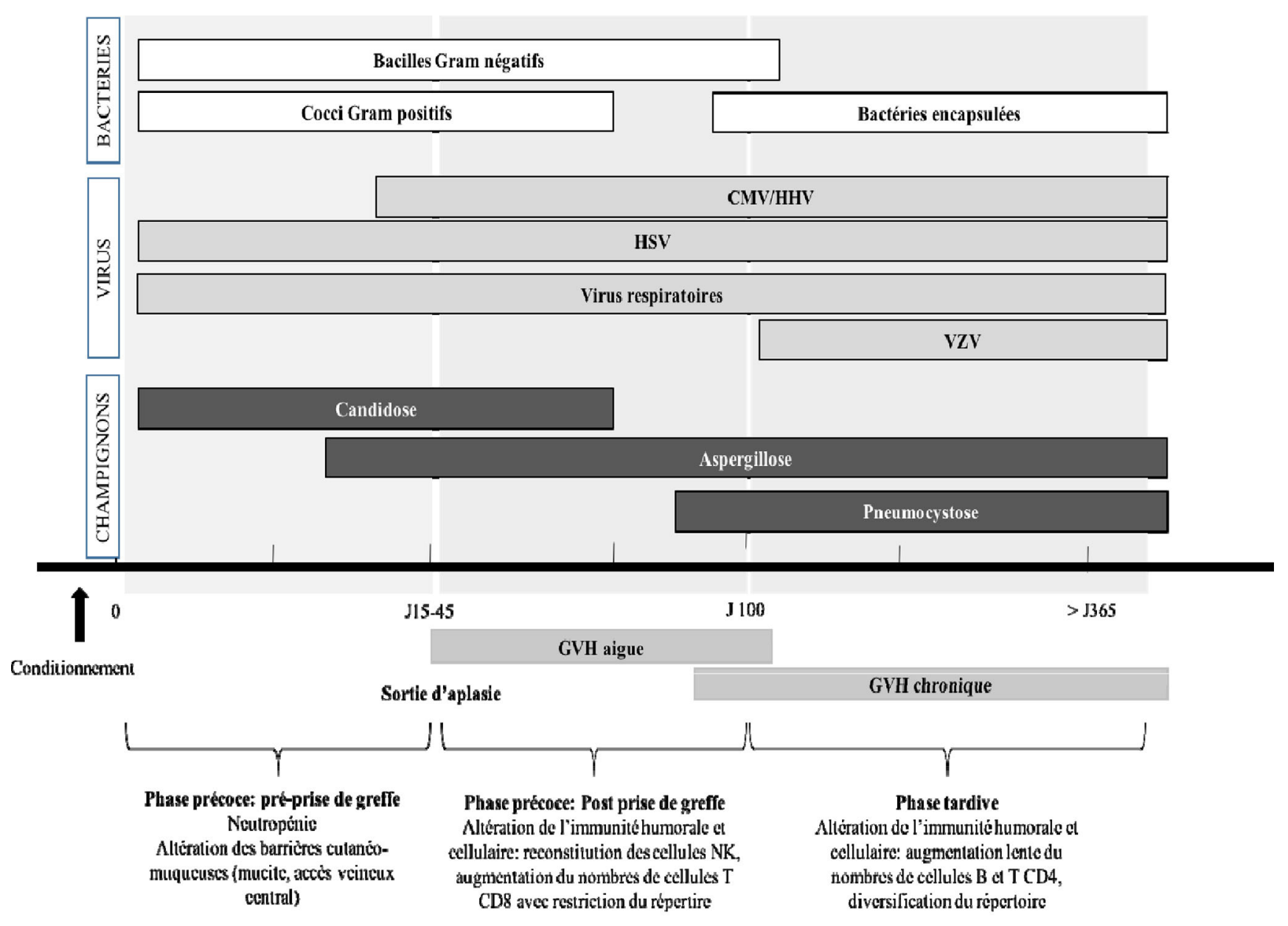

CMV : Cytomégalovirus, VZV : Varicelle zona virus, HSV : Herpès simplex virus, HHV : Human herpès virus

Fig. 1 Évolution du risque infectieux au cours de la greffe de moelle osseuse 
La tuberculose et les infections à mycobactérie atypique ne représentent pas un problème majeur au cours de la greffe de CSH [57], avec une incidence dix fois moindre qu'en transplantation d'organe solide (TOS). Le principal facteur de risque reste la naissance en zone d'endémie. La plupart des patients développent une infection après les 100 premiers jours de greffe, le plus souvent en cas de GVH [69]. À noter que les patients ayant bénéficié d'une autogreffe de CSH représentent $20 \%$ des cas de tuberculose dans cette population, en particulier en cas de LLC et notamment en cas de traitement préalable par alemtuzumab ou fludarabine $[57,70]$.

Enfin, tout au long de la période d'IS, les patients présentent un risque augmenté d'infection à virus respiratoires communautaires [57] (cf. infra).

\section{Transplantation d'organe solide}

Les complications infectieuses sont fréquentes dans cette population, et l'atteinte pulmonaire est au premier plan. Dans une étude prospective menée sur une période de six mois dans 35 centres européens, l'incidence estimée était de 10,1 épisodes/1 000 receveurs par année [71]. La fréquence est variable selon l'organe considéré, plus élevée après transplantation pulmonaire ou cardiaque [72]. En réanimation, les pneumonies représentent la première cause d'admission pour infection, jusqu'à $60 \%$ des cas chez les transplantés rénaux [3].

Le risque infectieux est principalement influencé par les traitements IS d'une part et les antécédents du patient (diabète, âge, transplantations multiples, immunisation mais aussi pays d'origine et voyages) d'autre part.

La plupart des IS utilisés au cours des greffes d'organes solides sont à l'origine d'un déficit de l'immunité cellulaire portant sur les lymphocytes $T$ favorisant la survenue d'infections opportunistes, bactériennes à germes intracellulaires ou à croissance lente (mycobactéries, Nocardia), virales (Herpesviridae dont CMV ou VZV), fongiques (Pneumocystose, Aspergillose) ou parasitaire. Les traitements peuvent également être responsable d'une hypogammaglobulinémie (rituximab, échange plasmatique) qui expose aux complications infectieuses déjà décrites [73]. Une neutropénie favorisée par les IS (Mycophénolate mofétil, sérum antilymphocytaire) ou par le traitement de certaines infections (ganciclovir, valganciclovir, cotrimoxazole) survient chez presque $30 \%$ des patients la première année, avec un risque d'infection propre [74].

Comme au cours de l'allogreffe de $\mathrm{CSH}$, le profil des infections évolue au cours du temps, selon les modifications du régime d'immunosuppression [75] :

- la période postopératoire précoce (premier mois) : elle est marquée par des infections bactériennes nosocomiales.
Il s'agit essentiellement de pneumonie d'inhalation, de pneumonies acquises sous ventilation mécanique et de localisations pulmonaires d'emboles septiques (à partir des dispositifs intravasculaires le plus souvent, bactériens ou fongiques à Candida $s p$.). Les germes les plus fréquemment rencontrés sont les bacilles à Gram négatif (E. coli, K. pneumoniae, P. aeruginosa, E. cloacae, $H$. influenzae) mais aussi $S$. aureus, résistant ou non à la méticilline. L'incidence est particulièrement marquée en cas de transplantation pulmonaire jusqu'à $60 \%$ des cas [76]. Les infections fongiques sont dominées par les candidoses invasives avec une incidence de $2 \%$ [77]. L'aspergillose reste rare à cette période en dehors des greffes réalisées en « super-urgence » chez des patients déjà hospitalisés en réanimation le plus souvent ou dans le cas particulier de la greffe pulmonaire avec un risque d'atteinte trachéobronchique à l'origine de déhiscence des anastomoses [78] ;

- $\mathrm{du} 1^{\mathrm{er}}$ au $6^{\mathrm{e}}-12^{\mathrm{e}}$ mois postgreffe : cette période est à haut risque d'infection, influencée par le traitement IS et son intensité en particulier en cas de rejet aigu [75].

Les infections respiratoires sont avant tout opportunistes : virales (CMV), bactériennes (nocardiose, mycobactéries), fongiques (aspergillose, mucormycose, cryptococcose, pneumocystose). Néanmoins, depuis l'instauration systématique de prophylaxies, les pneumonies à CMV et la pneumocystose sont devenues quasi virtuelles sur cette période $[66,72]$;

- après le $6^{\mathrm{e}}-12^{\mathrm{e}}$ mois postgreffe : en l'absence de dysfonction du greffon, le régime d'immunosuppression est habituellement allégé avec une diminution du risque infectieux. Les complications sont alors essentiellement communautaires : virus respiratoires, bactéries habituelles des pneumonies communautaires. Les patients présentant un rejet du greffon nécessitant une majoration du traitement IS trouvent le même risque que lors de la précédente période. Un certain nombre de patients peuvent néanmoins développer une infection opportuniste malgré la diminution du régime IS. Les germes fréquemment impliqués sont alors : Pneumocystis (du fait de l'arrêt fréquent de la prophylaxie à ce stade), certaines bactéries (Nocardia, Rhodococcus), les mycobactéries du complexe tuberculosis ou atypiques, les infections fongiques invasives (IFI) [Aspergillus, mucorales, champignons inhabituels] $[75,79]$.

Tout comme les patients avec greffe de $\mathrm{CSH}$, la pneumonie à CMV représentait autrefois la première cause de pneumonie virale, principalement au cours des six premiers mois postgreffe. Son incidence a largement régressé depuis la mise en place d'une prophylaxie systématique chez les patients à haut risque (Receveur-/Donneur+ $>$ Receveur+/ Donneur-) [66]. L'utilisation d'OKT3 et des autres thérapies 
antilymphocytaires (alemtuzumab, sérum antilymphocytaire) augmente ce risque. Elle s'associe à un risque accru d'autres complications opportunistes (pneumocystose, aspergillose), de dysfonction aiguë ou chronique du greffon de par les effets immunomodulateur du virus [66]. Les modalités du diagnostic et de traitement ne diffèrent pas de celles des patients avec allogreffe de $\mathrm{CSH}$.

De la même façon, la pneumocystose est devenue plus rare au cours des TOS, du fait de l'utilisation de prophylaxie $[79,80]$. L'incidence est de $10 \%$ actuellement et survient audelà des six premiers mois du fait de l'arrêt de la prophylaxie, généralement après majoration du traitement IS pour un épisode de rejet [80]. L'aspect clinique est peu spécifique, et l'imagerie thoracique retrouve habituellement une atteinte interstitielle bilatérale avec des opacités en verre dépoli pouvant progresser vers des condensations. La mortalité en réanimation est élevée de l'ordre de $40 \%$ [81], la précocité du traitement par cotrimoxazole étant le principal facteur pronostique, il doit être débuté chaque fois que le diagnostic est évoqué, sans attendre les résultats des prélèvements.

Les IFI sont dominées par les candidoses (2\%), l'aspergillose invasive $(0,2$ à $3,5 \%)$ et les cryptococcoses ( $1 \%)$ [77]. Les candidoses invasives surviennent essentiellement au cours du premier mois postgreffe, principalement après les transplantations d'organes intra-abdominaux ou cardiaques. L'API est la présentation la plus fréquente d'aspergillose invasive avec une mortalité supérieure à $50 \%$ [78], surtout en cas de transplantation hépatique ou rénale. La majorité des cas surviennent lors des trois premiers mois postgreffe, les facteurs de risque étant une période postopératoire compliquée, des infections bactériennes répétées, une réactivation $\mathrm{CMV}$, la survenue d'une insuffisance rénale [78]. Après trois mois, les sujets âgés ou ayant une IS lourde $\mathrm{du}$ fait d'une dysfonction du greffon sont les plus à risque $[78,82]$. Chez le patient transplanté pulmonaire, il peut s'agir de formes trachéobronchiques, se présentant comme des lésions nodulaires ou ulcérées, intéressant les zones anastomotiques, dont la mortalité de $25 \%$ peut atteindre $80 \%$ en cas de forme invasive associée [83]. La cryptococcose est la troisième IFI chez le patient transplanté, principalement en cas de greffe rénale ou cardiaque. Les patients recevant de fortes doses de corticoïdes ou de l'alemtuzumab sont particulièrement à risque. Le délai de survenue est de 16 à 21 mois avec une mortalité de l'ordre de $30 \%$ [77,82].

Les infections à mucorales (Mucormycosis ou Zygomycosis), Fusarium spp et Scedosporium spp sont en augmentation ces dernières années bien que l'incidence reste faible [77], de l'ordre de $3 \%$ de l'ensemble des IFI. L'insuffisance rénale, le diabète et l'administration préalable de voriconazole sont les facteurs de risque habituels de la mucormycose, dont l'atteinte pulmonaire est la localisation la plus fréquente et la mortalité de 40-50\% [84]. Des IFI endémiques inhabituelles en France (histoplasmose, blastomycoses, coccidioi- domycose) sont possibles en cas de séjours à l'étranger. La plupart des infections surviennent dans les deux ans après la greffe, mais des formes tardives sont possibles [85].

L'incidence de la tuberculose chez les patients avec TOS est de l'ordre de $3 \%$, et la mortalité élevée, jusqu'à $40 \%$ [86]. La distribution est bimodale, principalement au cours de la première année, puis avec un pic à deux ans [86]. Il s'agit surtout de la réactivation d'infection tuberculeuse latente (ITL) qui devrait pourtant être systématiquement dépistée et traitée avant transplantation. Les mycobactéries atypiques sont plus fréquentes chez les patients avec TOS, plus fréquentes en cas de greffe cardiaque ou pulmonaire (de 0,2 à $3 \%$ ) [87]. Le diagnostic des formes pulmonaires est difficile et doit faire éliminer une autre cause d'infection. Le traitement repose sur une antibiothérapie adaptée à la souche identifiée, la chirurgie et la diminution du traitement IS [88].

La nocardiose est une infection bactérienne rare (1 à $3 \%$ des greffés), dont le risque est directement lié à l'intensité de l'immunosuppression en particulier la corticothérapie, les anticalcineurines et les thérapies ciblant les lymphocytes $\mathrm{T}$ [89]. Le diagnostic sera discuté devant une atteinte pulmonaire isolée (organe le plus souvent atteint, avec une présentation nodulaire volontiers excavée au scanner, avec parfois un signe du Halo) ou disséminée dans $40 \%$ des cas (abcès cérébraux, atteinte cutanée). Il est important de noter que les faibles doses de cotrimoxazole utilisées en TOS ne semblent pas suffisantes pour prévenir le risque de nocardiose [90].

\section{Maladies de système}

L'infection est le premier motif d'hospitalisation des patients avec MS en réanimation, et l'atteinte respiratoire est souvent au premier plan. Ainsi, dans une série de 381 patients avec MS hospitalisés en réanimation, $56 \%$ l'étaient pour une insuffisance respiratoire aiguë, secondaire à une pneumonie dans $44 \%$ des cas [4]. Dans une cohorte européenne portant sur 3658 patients atteints de lupus érythémateux systémique (LES) suivis sur une période de deux ans, le taux d'incidence pour des infections était de 29,2 pour 1000 patients-année avec une prédominance de pneumonie $(35,5 \%)$ [91]. Le risque infectieux est lié au déficit immunitaire secondaire à la maladie et aux IS.

Ce déficit immunitaire propre à la maladie est bien documenté au cours du LES, avec une hypocomplémentémie constitutionnelle ou acquise, un déficit de l'immunité cellulaire, une asplénie fonctionnelle et une diminution de la production d'Ig, rendant compte d'une fréquence accrue d'infections [91]. Au cours des vascularites à ANCA, le risque est avant tout lié à l'importance de l'immunosuppression nécessaire pour contrôler ces maladies agressives, expliquant des taux de mortalité élevés de l'ordre de $10-15 \%$ à un an dans cette situation [92]. 
Dans le cas particulier de la granulomatose avec polyangéite (ex-maladie de Wegener), la survenue de lésions excavées peut favoriser une surinfection bactérienne ou fongique (aspergillome).

Les infections sont le plus souvent bactériennes. Les germes fréquemment retrouvés sont : $S$. pneumoniae, $S$. aureus et les bacilles à Gram négatif ( $E$. coli, P. aeruginosa). Ces infections sont fréquentes au cours de la première année d'évolution puis diminuent au cours du temps. Les infections à mycobactéries, principalement du complexe tuberculosis, sont décrites avec une incidence de 0,66 à $15 \%$ selon les populations et les maladies [93]. Il s'agit surtout de la réactivation d'ITL, suivant généralement l'intensification du traitement à l'occasion d'une poussée de la maladie. Les infections opportunistes (pneumocystose, nocardiose, IFI) sont exclusivement liées à l'utilisation des corticoïdes à fortes doses et aux IS (cf. infra).

La principale difficulté est de ne pas méconnaître une infection (volontiers masquée par les effets antiinflammatoires des IS) devant des éléments pouvant faire évoquer à tort une poussée de la maladie de fond, justifiant une attitude volontiers invasive et systématique.

\section{Déficits immunitaires cellulaires iatrogéniques}

La première cause de déficit immunitaire de l'adulte aujourd'hui reste l'utilisation d'IS et d'autres thérapies antitumorales [18]. La plupart de ces traitements sont utilisés en TOS ou en transplantation de greffe de $\mathrm{CSH}$ afin de diminuer le risque de rejet, dans le traitement des maladies autoimmunes afin d'obtenir une rémission de la maladie de fond et en pathologies malignes solides ou hématologiques. Le tableau 2 représente les principaux déficits immunitaires iatrogéniques et les germes associés.

En fonction de la cible et du mécanisme d'action, on distingue plusieurs types de médicaments IS.

\section{- Corticoïdes}

Les corticoïdes exercent leurs propriétés immunosuppressives via un grand nombre de mécanismes : inhibition de l'activation, prolifération et différenciation des lymphocytes $\mathrm{T}$, altération de la phagocytose, diminution du chimiotactisme et de la migration tissulaire des cellules mononucléées. Le risque est directement lié à la durée de traitement et à la dose. Dans une méta-analyse ancienne, portant sur 2111 patients, une dose supérieure à $10 \mathrm{mg} / \mathrm{j}$ d'équivalent prednisone (ou une dose cumulée supérieure à $700 \mathrm{mg}$ ) et une durée supérieure à 21 jours étaient associées à un risque relatif d'infections de 1,6 [94]. Il s'agit avant tout d'infections pulmonaires à germes banals ( $S$. pneumoniae, $S$. aureus, Entérobactéries) [95]. L'exposition chronique aux corticoïdes, en revanche, augmente le risque d'infections opportunistes
(42/100 patients-année dans le lupus par exemple [96]), en particulier en cas d'association à d'autres facteurs de risque (autres IS, diabète), fréquemment retrouvés dans les populations concernées. La tuberculose est une complication fréquente. Dans une étude cas-témoins conduite entre 1990 et 2001, Jick et al. ont ainsi objectivé un OR ajusté de 4,9 pour l'utilisation des corticoïdes sur le risque de tuberculose. Ces fortes doses sont par ailleurs associées à un risque accru de tuberculose miliaire. Le risque est particulièrement augmenté dans les deux ans suivant l'initiation du traitement [97]. La pneumocystose est une autre complication fréquente. Les patients recevant des doses élevées $(>20 \mathrm{mg} / \mathrm{j}$ pendant quatre semaines ou bolus) sont particulièrement à risque, y compris au cours des hémopathies ou des tumeurs solides, notamment cérébrales [98]. La corticothérapie est un facteur de risque d'infection à cryptocoque ( $30 \%$ des cas), d'API, de zygomycose et de candidémie [99]. D'autres agents infectieux comme la nocardiose, l'anguillulose maligne (responsable d'une pneumonie interstitielle souvent associée à d'autres localisations viscérales), les mycoses endémiques sont également décrits [95].

- Immunosuppresseurs « traditionnels »

Il s'agit des agents cytotoxiques (cyclophosphamide, azathioprine, méthotrexate), des analogues des purines (mycophénolate mofétil $\left.{ }^{\circledR}\right)$, des inhibiteurs de la calcineurine (ciclosporine, tacrolimus) qui majorent le risque infectieux principalement du fait de leur toxicité hématologique (neutropénie, lymphopénie CD4 et B, hypogammaglobulinémie) [100]. Là encore, la dose et les conditions d'utilisation semblent largement influencer le risque d'infection. Le méthotrexate, y compris à faible dose $(7,5-25 \mathrm{mg} /$ semaine $)$, est réputé prédisposer aux infections en particulier respiratoires, avec une incidence estimée à 17 patients-année [100]. Ce risque est aujourd'hui remis en question dans les travaux les plus récents [101]. Outre le risque d'infection bactérienne favorisée par la neutropénie induite sous traitement, de nombreux case reports ont souligné le risque d'infections opportunistes (pneumocystose, cryptococcose, aspergillose, CMV) [102]. Cependant, la co-utilisation de corticoïdes semble être ici un facteur confondant, justifiant qu'aucune prophylaxie spécifique ne soit actuellement recommandée pour ces patients [101]. L'Endoxan ${ }^{\circledR}$, utilisé à forte dose au cours du lupus ou des vascularites, est associé à un risque d'infections bactériennes (principalement $S$. aureus, $P$. aeruginosa, $H$. influenzae) ou opportunistes (pneumocystose principalement) via une leucopénie et/ou une neutropénie induite [100]. La coprescription de corticoïdes semble être là aussi un facteur majeur, notamment au cours des vascularites à ANCA où l'incidence de la pneumocystose est historiquement de $20 \%$ [103]. 
Tableau 2 Principaux déficits immunitaires iatrogéniques

\begin{tabular}{|c|c|c|c|}
\hline Molécule & Indication & Type de déficit & Germes fréquemment associés \\
\hline Corticoïdes & MAI, greffe, hémopathies & $\begin{array}{l}\text { Déficit } \mathrm{T} \text { et fonctions } \\
\text { monocytes-macrophages }\end{array}$ & $\begin{array}{l}\text { Bactérien non opportuniste, PCP, TB, } \\
\text { mycobactéries atypiques, cryptococcose, IFI }\end{array}$ \\
\hline $\begin{array}{l}\text { Analogues des purines } \\
\text { (fludarabine, cladrabine, } \\
\text { cytarabine) }\end{array}$ & $\begin{array}{l}\text { LLC, LNH, leucémie } \\
\text { à tricholeucocytes }\end{array}$ & PNN, déficit $T+B$ & $\begin{array}{l}\text { Bactérien non opportuniste, mycobactérie, } \\
\text { nocardiose, IFI, PCP, VZV }\end{array}$ \\
\hline Cyclophosphamide & MAI, hémopathies & Déficit $B$, neutropénie & Bactérien non opportuniste, PCP, IFI \\
\hline $\begin{array}{l}\text { Azathioprine, } \\
\text { Mycophénolate Mofétil }\end{array}$ & MAI, greffe & HypoG, PNN, déficit $\mathrm{T}+\mathrm{B}$ & Bactérien non opportuniste, CMV, VZV \\
\hline Méthotrexate & MAI, LNH & PNN & $\begin{array}{l}\text { Bactérien non opportuniste, nocardiose, TB, } \\
\text { PCP, IFI }\end{array}$ \\
\hline $\begin{array}{l}\text { Rituximab } \\
(\text { anti-CD20) }\end{array}$ & LNH, MAI & $\begin{array}{l}\text { Déficit B, HypoG, +/- } \\
\text { PNN }\end{array}$ & Bactérien non opportuniste, PCP \\
\hline $\begin{array}{l}\text { Alemtuzumab } \\
\text { (anti-CD52) }\end{array}$ & LLC, LNH, greffe & Déficit $T+B$ & $\begin{array}{l}\text { Bactérien non opportuniste, CMV, } \\
\text { Adénovirus, IFI, PCP, TB, mycobactéries } \\
\text { atypiques, Nocardia }\end{array}$ \\
\hline $\begin{array}{l}\text { Anti-TNF alpha } \\
\text { Infliximab } \\
\text { Certolizumab } \\
\text { Golimumab } \\
\text { Adalimumab } \\
\text { Étanercept }\end{array}$ & MAI & $\begin{array}{l}\text { Fonction monocytes- } \\
\text { macrophages, HypoG, } \\
\text { cascade cytokinique }\end{array}$ & $\begin{array}{l}\text { Bactérien non opportuniste, légionellose, } \\
\text { nocardiose, TB, mycobactéries atypiques, } \\
\text { histoplasmose, cryptococcose, IFI }\end{array}$ \\
\hline $\begin{array}{l}\text { Tofacinib } \\
\text { (anti-JAK1/3) }\end{array}$ & MAI & cascade cytokinique & Mycobactéries, cryptococcose, VZV \\
\hline $\begin{array}{l}\text { Ustékinumab } \\
\text { (Anti-IL12/23) }\end{array}$ & MAI & cascade cytokinique & Mycobactéries, VZV \\
\hline $\begin{array}{l}\text { Daclizumab } \\
(\mathrm{IL}-2)\end{array}$ & greffe & Déficit $\mathrm{T}$ & $\begin{array}{l}\text { Bactérien non opportuniste, IFI, nocardiose, } \\
\text { légionellose, mycobactéries, adénovirus, } \\
\text { CMV }\end{array}$ \\
\hline Abatacept & MAI & Déficit $\mathrm{T}$ & $\begin{array}{l}\text { Bactérien non opportuniste, légionellose, } \\
\text { mycobactéries, PCP }\end{array}$ \\
\hline $\begin{array}{l}\text { Tocilizumab } \\
\text { (anti-IL-6) }\end{array}$ & MAI & $\begin{array}{l}\text { Fonctions PNN/ } \\
\text { macrophages }\end{array}$ & $\begin{array}{l}\text { Bactérien non opportuniste, mycobactéries, } \\
\text { PCP, VZV }\end{array}$ \\
\hline Anti-VEGF/EGFR & Tumeurs solides & PNN & Bactérien non opportuniste \\
\hline $\begin{array}{l}\text { Anticytokines } \\
\text { (anti-Il-1, Il1-Ra) }\end{array}$ & MAI & cascade cytokinique & Bactérien non opportuniste (Pneumocoque) \\
\hline $\begin{array}{l}\text { Sérum } \\
\text { antilymphocytaire } \\
\text { et OKT3 }\end{array}$ & greffe & Déficit $\mathrm{T}+\mathrm{B}$ & $\begin{array}{l}\text { Bactérien non opportuniste, nocardiose, } \\
\text { PCP, IFI, cryptococcose, CMV, VZV, } \\
\text { adénovirus }\end{array}$ \\
\hline Inhibiteur de mTOR & $\begin{array}{l}\text { Greffe, cancérologie solide, } \\
\text { hémopathies }\end{array}$ & Déficit $\mathrm{T}+\mathrm{B}$ & Bactérien non opportuniste, IFI \\
\hline
\end{tabular}




\section{- Biothérapies}

Les biothérapies ont transformé le pronostic des maladies auto-immunes (MICI, rhumatismes inflammatoires...) et tumorales (lymphomes, tumeurs solides) en ciblant certaines étapes clés de l'inflammation ou de la réponse immunitaire. Le blocage de ces voies de signalisation induit des déficits immunitaires qui peuvent être attendus, propres à la cible considérée, ou inattendus, compte tenu des dialogues complexes entre les différents acteurs de l'immunité et de la coprescription d'autres IS. Comparativement aux traitements standard, le risque infectieux sous biothérapies est augmenté. Ainsi, dans une méta-analyse comprenant 106 essais cliniques dans la polyarthrite rhumatoïde, l'utilisation de biothérapie était associée à un risque d'infection avec un OR de 1,31 [1,09-1,58]. Outre la molécule considérée, la dose, les comorbidités et l'utilisation concomitante d'autres traitements (corticoïdes, autres IS) sont les principaux facteurs de risque $[9,104]$.

\section{- Anti-TNF $\alpha$}

Le TNF $\alpha$ est une molécule clé de l'inflammation, qui joue un rôle majeur dans le contrôle et l'élimination de nombreux agents infectieux [105]. Les inhibiteurs solubles (étanercept) ou membranaires (infliximab, certolizumab, golimumab, adalimumab) sont associés à la survenue de complications infectieuses, en particulier à germes intracellulaires (bactériens ou fongiques), liées aux blocages des fonctions des cellules mononucléées. Ce risque est particulièrement élevé au cours des premiers mois de traitement et plus fréquent sous infliximab [106]. Le poumon est le site le plus fréquent [107,108]. Il s'agit surtout d'infections bactériennes à pyogènes [9]. La réactivation d'une ITL est une complication aujourd'hui bien connue ayant conduit à la mise en place d'un dépistage systématique dans la plupart des pays [9]. En l'absence de dépistage, le risque de développer une infection tuberculeuse est multiplié par un facteur 7 [109]. Il varie en fonction de l'origine géographique et du type de molécule (infliximab) [110]. L'étude française du registre RATIO (colligeant les événements infectieux sous anti-TNF $\alpha$ ) souligne la fréquence des formes disséminées (55\%) et les limites de la mise en œuvre du dépistage non ou mal conduit chez la moitié des patients et l'insuffisance des performances de l'IDR à la tuberculine, négative dans deux tiers des cas [110].

Les infections opportunistes sont également plus fréquentes. La légionellose est ainsi 16 à 21 fois plus fréquente chez les patients sous anti-TNF $\alpha$ selon les résultats du registre français [111]. Cette population est également à risque d'IFI endémique ou non. L'histoplasmose et l'aspergillose sont les complications les plus décrites, avec une incidence selon les données de la FDA de 18,78 et 8,6/100 000 patients respectivement [112]. Plusieurs séries rapportent des formes pulmo- naires ou pleurales de cryptococcoses, dont le diagnostic peut être rendu difficile par le manque de sensibilité de l'antigène soluble cryptocoque chez les patients sous anti-TNF $\alpha$ [113].

\section{- Rituximab}

Cet anticorps anti-CD20 ciblant les lymphocytes B est largement utilisé dans le traitement à la fois des hémopathies lymphoïdes et des pathologies auto-immunes. La tolérance est excellente et le risque d'infection faible. Plusieurs mécanismes sont en cause (lymphopénie B mais aussi T, neutropénie retardée, rare hypogammaglobulinémie). Dans le cadre des pathologies auto-immunes, ce risque est de 5 à 6 cas/100 patients-année, et le tractus respiratoire représente la première localisation habituellement à germes pyogènes $[20,114]$. Le risque d'infection opportuniste est débattu et le résultat des études contradictoires [115-117], et aucune recommandation n'existe à l'heure actuelle quant à la justification d'une prophylaxie systématique lors de l'utilisation en monothérapie [118]. La pneumocystose est la principale complication décrite [119], mais dont le risque paraît en partie influencé par les cotraitements (chimiothérapies cytotoxiques, analogues des purines, corticoïdes). Le risque de réactivation virale (herpès virus) est également augmenté [20].

\section{- Alemtuzumab}

Cet anticorps monoclonal dirigé contre le CD52 cible l'ensemble des lymphocytes (B, T, NK), à l'origine d'une lymphopénie profonde. Son utilisation est associée à un risque majeur d'infection à P. jirovecii, Cryptococcus neoformans et CMV [120,121].

\section{Cas particulier des virus respiratoires}

Les virus respiratoires communautaires sont des causes d'infections de plus en plus reconnues chez les patients immunodéprimés. Le développement de PCR multiplex ayant une sensibilité supérieure à $90 \%$ a permis de mieux reconnaitre ce risque [122]. La recherche s'effectue le plus souvent sur un prélèvement nasopharyngé, non invasif et généralement suffisant pour confirmer le diagnostic [122]. Chez les sujets ayant une atteinte des voies respiratoires basses, différentes sociétés savantes recommandent l'obtention d'un prélèvement profond (crachat induit, aspiration trachéale, LBA) qui permet de confirmer l'atteinte pulmonaire et rechercher d'autres pathogènes associés $[123,124]$. Chez les patients atteints de déficit de l'immunité humorale, le risque est avant tout la survenue d'une surinfection bactérienne, à $S$. pneumoniae en particulier. La problématique des infections virales est avant tout l'apanage des patients ayant un déficit de l'immunité cellulaire 
quelle qu'en soit l'origine (chimiothérapie antitumorale, greffe de CSH, TOS, infection par le VIH) [18]. Le Rhinovirus, le virus Infuenzae (agent de la grippe saisonnière), le virus Parainfluenzae, le virus respiratoire syncytial (VRS), le métapneumovirus humain sont les agents les plus souvent impliqués [42]. Les quatre derniers sont volontiers responsables d'atteintes des voies aériennes basses, avec une incidence de 5 à $50 \%$ et une mortalité pouvant aller jusqu'à $50 \%$ selon le type d'immunodépression et le virus considéré $[125,126]$. Les infections à virus Influenzae de type A ou B peuvent être particulièrement graves dans cette population, notamment par la survenue de pneumonie spécifique [125] et la fréquence des co-infections bactériennes, virales (CMV) ou fongiques jusqu'à $30 \%$ des cas [127].

Quel que soit le virus considéré, la présentation clinique diffère peu de celle des sujets immunocompétents (fièvre, myalgies, rhinorrhée et signes respiratoires). Il faut souligner le risque d'acquisition nosocomiale qui justifie une recherche systématique, y compris chez les patients déjà hospitalisés [125]. Les ressources thérapeutiques sont limitées. Concernant l'infection grippale, l'utilisation précoce (dans les premières 24 heures suivant le début des symptômes) d'oseltamivir pourrait diminuer le risque de complications et de décès [126]. Les risques de résistance sont plus élevés dans cette population compte tenu de la virémie souvent plus prolongée. En cas d'échec (suspecté devant une aggravation ou une persistance des manifestations au-delà de dix jours) ou d'impossibilité d'utilisation de la voie orale, l'utilisation de zanamivir ou de peramivir intraveineux est décrite [128]. Les formes sévères d'infection à VRS ou à virus parainfluenzae peuvent bénéficier d'Ig intraveineuse et/ou de ribavirine [126]. Dans tous les cas, lorsqu'une atteinte des voies aériennes basses est suspectée, une antibiothérapie ciblant $S$. pneumoniae, $S$ aureus et $H$. influenzae devra être débutée.

\section{Orientation diagnostique}

La stratégie diagnostique devant une détresse respiratoire supposée infectieuse chez un patient immunodéprimé repose sur une évaluation clinique rigoureuse, l'utilisation d'outils microbiologiques invasifs ou non et d'examens d'imagerie. Azoulay et Schlemmer ont proposé une approche standardisée et synthétique, reposant sur l'acronyme DIRECT [129] : le délai depuis le début de l'immunodépression (début de la chimiothérapie, date de TOS), le type d'immunodépression (humoral, cellulaire, neutropénie), l'aspect radiologique, l'expérience clinique et la connaissance de la littérature (par exemple, germes encapsulés et déficit de l'immunité humorale ou pneumocystose chez les patients recevant des analogues des purines) et l'aspect à la tomodensitométrie thoracique. Cet examen est devenu la référence et supplante largement la radiographie thoracique. Certains patterns sont évocateurs d'un agent infectieux (Tableau 3). Cependant, il doit toujours être interprété en fonction du contexte clinique, aucun aspect n'étant totalement spécifique d'une cause donnée.

L'approche DIRECT a été validée chez le patient d'oncohématologie [8], mais peut à notre sens s'appliquer quel que soit le type d'immunodépression. La présentation clinique (rapidité des symptômes, manifestations extrarespiratoires), l'anamnèse (antécédents infectieux, contexte nosocomial ou communautaire, notion de contage) et l'observance d'éventuelles prophylaxies (cotrimoxazole, valgancyclovir) sont des éléments clés. Ainsi, la probabilité prétest de pneumocystose chez un patient prenant de façon rigoureuse une prophylaxie par cotrimoxazole devient extrêmement faible. L'ensemble de ces éléments va permettre de guider les examens complémentaires et le traitement probabiliste [129]. Le panel des outils diagnostiques disponibles est aujourd'hui large (Tableaux 4, 5,6). L'antigénurie légionnelle sera systématiquement demandée. Les examens non invasifs sanguins (hémocultures standard, hémocultures sur milieu spécialisé en cas de suspicion de germes à croissance lente, sérologies des germes intracellulaires, PCR CMV, VZV, HSV, adénovirus, $\beta$-D-glucane, antigénémie aspergillaire) seront demandés en fonction de l'orientation clinique de même que les examens respiratoires (bactériologie standard, mycobactériologie, mycologie sur crachats ou expectoration induite, PCR multiplex des agents viraux respiratoires sur aspiration nasopharyngée). La performance de ces examens doit être discutée en fonction de la pathologie sous-jacente. Ainsi, si l'utilité de l'expectoration induite pour le diagnostic de pneumocystose est largement établie, le caractère paucikystique de la maladie chez les immunodéprimés non VIH rend son intérêt plus limité [98]. L'antigène aspergillaire (ou galactomannane) dans le sang est un critère diagnostique reconnu d'API [45], avec une sensibilité de $78 \%$ et une spécificité de $90 \%$. Chez les sujets non neutropéniques, ces performances sont plus faibles, avec une sensibilité de 21 à $58,6 \%$ chez les patients transplantés d'organes solides [82]. La détection de l'antigène aspergillaire dans le LBA semble avoir des performances très intéressantes, avec une sensibilité de 60 à $80 \%$ et une spécificité de 90 à $96 \%$ [82]. Des faux-positifs chez les patients présentant une infection à Histoplasma, Fusarium et Blastomyces ont été décrits. Le $\beta$ D-glucane est un composant de la paroi de nombreux champignons (Aspergillus, Pneumocystis, Candida), dont le dosage est encore peu réalisé en routine et dont la détection dans le sang pourrait aider à suspecter une infection fongique invasive sans présumer de son type en dehors des infections à Mucorales [44,82]. Des techniques de PCR sont depuis peu en cours de développement (Aspergillus et Mucorales) et devraient permettre dans les années à venir de faciliter le diagnostic des IFI. À l'heure actuelle, seule la PCR Pneumocystis (sur expectoration induite ou LBA) est validée 
Tableau 3 Principaux aspects scanographiques et pathogènes fréquemment en cause au cours des pneumonies de patients immunodéprimés

\begin{tabular}{|c|c|c|c|c|c|c|c|c|c|c|}
\hline & \multicolumn{2}{|c|}{ Consolidation } & \multicolumn{2}{|c|}{ Verre dépoli } & \multirow{2}{*}{$\begin{array}{l}\text { Atteinte } \\
\text { septale }\end{array}$} & \multirow{2}{*}{$\begin{array}{l}\text { Atteinte } \\
\text { pleurale }\end{array}$} & \multirow{2}{*}{$\begin{array}{l}\text { Excava- } \\
\text { tion }\end{array}$} & \multirow[t]{2}{*}{ Nodule } & \multicolumn{2}{|c|}{ Micronodules } \\
\hline & Lobaire & $\begin{array}{l}\text { Multifo- } \\
\text { cale }\end{array}$ & Diffus & Focal & & & & & $\begin{array}{l}\text { Centro- } \\
\text { lobu- } \\
\text { laire }^{a}\end{array}$ & $\begin{array}{l}\text { Aléa- } \\
\text { toire }\end{array}$ \\
\hline Pneumocoque & +++ & + & & & & ++ & & & & \\
\hline Bronchopneumonie $^{\mathrm{b}}$ & & +++ & & & & & & & +++ & \\
\hline Bactériémie & & +++ & & & & & + & ++ & & ++ \\
\hline Rhodoccocus & ++ & & & & & & + & & & \\
\hline Nocardia & & & & & & & ++ & +++ & & \\
\hline Légionnelle & ++ & + & & & ++ & ++ & & & & \\
\hline $\begin{array}{l}\text { Mycoplasme, } \\
\text { Chlamydia pneumo- } \\
\text { niae }\end{array}$ & + & & & & ++ & & & & ++ & \\
\hline M. tuberculosis & ++ & & & + & & ++ & +++ & ++ & ++ & +++ \\
\hline M. atypiques & & & & & & & ++ & ++ & ++ & \\
\hline Virus & & & +++ & ++ & +++ & & & + & +++ & \\
\hline Aspergillose & & & & $\begin{array}{l}++ \\
\text { (halo) }\end{array}$ & & & ++ & ++ & +++ & \\
\hline Pneumocystose & & & +++ & & +++ & & & & & \\
\hline Candidose & & & & & & & & ++ & & ++ \\
\hline Mucormycose & & & & ++ & & & ++ & ++ & & \\
\hline Cryptococcose & & & + & + & & ++ & ++ & ++ & & \\
\hline Histoplasmose & ++ & ++ & & & ++ & & & ++ & & ++ \\
\hline
\end{tabular}

$[98,130]$. Du fait d'une très grande sensibilité, la distinction entre colonisation et infection reste débattue. Dans le cas spécifique de la pneumocystose du sujet non VIH, en cas d'immunofluorescence négative, une PCR négative élimine le diagnostic.

La place du LBA dans la prise en charge des infections respiratoires chez les patients immunodéprimés n'est pas consensuelle. S'il reste l'examen de référence, sa rentabilité diagnostique ne dépasse pas les $55 \%$ sur le plan microbiologique dans ce cadre [81]. Une étude randomisée en réanimation a comparé une stratégie non invasive et la réalisation d'un LBA chez des patients immunodéprimés. Cet essai ne retrouve pas de différence en termes de rentabilité diagnostique et confirme la bonne tolérance du LBA réalisé en réanimation [131]. Si l'indication est large chez le patient ventilé, elle se discute en l'absence de documentation microbiologique ou d'évolution défavorable sous traitement ou lorsque la suspicion d'infection opportuniste est forte, mais que la stratégie non invasive ne peut aboutir à un diagnostic rapide, tout en évaluant le risque de dégradation clinique à mettre en balance avec les bénéfices attendus.

\section{Traitement probabiliste}

L'antibiothérapie probabiliste découle des données issues de l'étape précédente qui oriente sur les germes supposés en cause et tient compte des colonisations connues. Les germes communautaires étant les plus fréquemment retrouvés quel que soit le type de déficit immunitaire, l'antibiothérapie devra couvrir $S$. pneumoniae et les entérobactéries (E. coli) avec une céphalosporine de troisième génération par exemple. En cas de neutropénie ou d'infection nosocomiale, le spectre sera élargi à $P$. aeruginosa. Le choix de la molécule dépendra aussi du profil de résistance locale et des antériorités du patient. Chez les patients hospitalisés, soumis à une pression antibiotique importante, notamment en hématologie, la prise en compte des bacilles à Gram négatif porteurs de bêtalactamases à spectre élargi (BLSE) reste nécessaire. En cas de mucite marquée ou de suspicion d'infection de cathéter et, en particulier, si la sémiologie radiologique est évocatrice d'une dissémination hématogène, l'élargissement du spectre aux germes à Gram positif est nécessaire (vancomycine ou linézolide) [42,132]. 
Tableau 4 Principaux germes impliqués dans les affections respiratoires de l'immunodéprimé et outils diagnostiques disponibles

\begin{tabular}{|c|c|c|c|}
\hline Pathogène & Examens non invasifs & LBA & Biopsie \\
\hline Infection à bactéries extracellulaires & Expectoration & $\begin{array}{l}++ \\
\text { (examen direct, culture) }\end{array}$ & $+^{\mathrm{a}}$ \\
\hline Legionella pneumophila & $\begin{array}{l}\text { Antigène urinaire, } \mathrm{PCR} \\
\text { sur prélèvement respiratoire }\end{array}$ & $\begin{array}{l}+/- \\
\text { (culture, PCR) }\end{array}$ & \\
\hline Mycoplasme, Chlamydia pneumoniae & $\begin{array}{l}\text { Sérologies, PCR Mycoplasma } \\
\text { sur prélèvement nasopharyngé }\end{array}$ & $\begin{array}{l}+/- \\
\text { PCR Mycoplasma }\end{array}$ & \\
\hline $\begin{array}{l}\text { Dissémination hématogène } \\
\text { bactérienne }\end{array}$ & Hémoculture & & \\
\hline Mycobactéries & Expectoration, tubage gastrique & $\begin{array}{l}++ \\
\text { (examen direct, culture) }\end{array}$ & + \\
\hline Virus respiratoires & PCR sur prélèvement nasopharyngé & $\begin{array}{l}+ \\
(\mathrm{PCR})\end{array}$ & \\
\hline CMV, VZV, HSV & PCR sang & $\begin{array}{l}+ \\
(\mathrm{PCR})\end{array}$ & \\
\hline Pneumocystose & $\begin{array}{l}\text { Expectoration induite } \\
\text { (colorations, immunofluorescence, } \\
\text { PCR), BD-glucane }\end{array}$ & $\begin{array}{l}++ \\
\text { (colorations, } \\
\text { immunofluorescence, } \\
\text { PCR) }\end{array}$ & \\
\hline Aspergillose & $\begin{array}{l}\text { Antigène galactomannane (sang, } \\
\text { expectorarion), BD-glucane }\end{array}$ & $\begin{array}{l}++ \\
\text { (antigène } \\
\text { galactomannane, examen } \\
\text { direct, culture) }\end{array}$ & + \\
\hline Candidose & Hémocultures, BD-glucane & & \\
\hline Mucorales & & $\begin{array}{l}++ \\
\text { (examen direct, culture, } \\
\text { PCR) }\end{array}$ & ++ \\
\hline Cryptococcose & $\begin{array}{l}\text { Hémoculture } \\
\text { Antigène spécifique circulant }\end{array}$ & $\begin{array}{l}+ \\
\text { (culture) }\end{array}$ & \\
\hline Toxoplasmose & PCR sang & & \\
\hline Histoplasmose & $\begin{array}{l}\text { Expectoration, Moelle osseuse } \\
\text { (examen direct, culture) } \\
\text { Antigène spécifique (sang, urines), } \\
\text { Antigène galactomannane }\end{array}$ & $\begin{array}{l}++ \\
\text { (examen direct, culture, } \\
\text { RT-PCR) }\end{array}$ & + \\
\hline
\end{tabular}

Dans tous les cas, un macrolide (la spiramycine étant la molécule présentant le moins d'interactions avec les IS) ou une quinolone ciblant L. pneumophila sera instauré. En période d'épidémie grippale, un antiviral (oseltamivir) sera débuté sans attendre le résultat des prélèvements respiratoires, l'administration précoce étant associée à une diminution de la mortalité et du recours à la ventilation mécanique [127].

En cas de déficit de l'immunité cellulaire, un aspect de pneumonie interstitielle fera débuter un traitement par cotrimoxazole $(20 \mathrm{mg} / \mathrm{kg}$ par jour de triméthoprime en trois ou quatre injections) compte tenu du pronostic sombre de la pneumocystose sur ce terrain en cas de retard thérapeutique [130].

Devant une atteinte respiratoire évocatrice d'une IFI, dans l'attente de l'identification, le traitement empirique recommandé est l'amphotéricine $\mathrm{B}$ liposomale à la dose de $3 \mathrm{mg} / \mathrm{kg}$ par jour [132] compte tenu du taux élevé d'échec thérapeutique avec la caspofungine en cas d'API. S'il s'agit d'une candidémie compliquée de localisation pulmonaire, compte tenu du taux élevé de résistance aux azolés (38\%) dans cette situation [133], il est recommandé d'utiliser une échinocandine en traitement probabiliste. En cas d'API probable ou prouvée, le voriconazole sera préféré [45]. La 


\begin{tabular}{|ll}
\hline Tableau 5 Examens non invasifs dans la démarche diagnostique d'une pneumonie du sujet immunodéprim \\
\hline Imagerie & Radiographie thoracique \\
Expectorations & Scanner thoracique avec coupes millimétriques \\
& Bactéries \\
& Mycobactéries \\
& Champignons (Aspergillus sp.) \\
Expectoration induite & Pneumocystis jirovecii \\
& (MGG, immunofluorescence, PCR) \\
Aspiration nasopharyngée & PCR virus respiratoires \\
& PCR Mycoplasma pneumoniae \\
Sang & Hémocultures \\
& Sérologies : Mycoplasme, Chlamydia, Legionella \\
& PCR virus herpès (CMV, HSV, VZV) \\
& Antigène aspergillaire \\
& BD-glucane \\
& Antigène sérique cryptocoque \\
& PCR Toxoplasma gondii \\
& Antigénurie légionelle
\end{tabular}

CMV : cytomégalovirus ; VZV : varicelle zona virus ; HSV : herpès simplex virus ; PCR : polymerase chain reaction ; MGG : may grumwald giemsa

Tableau 6 Les dix points clés

L'insuffisance respiratoire aiguë est une complication fréquente du patient immunodéprimé

L'absence de diagnostic étiologique est associée à une surmortalité

L'interrogatoire, l'examen clinique et les données de la tomodensitométrie thoracique sont les éléments clés de la démarche diagnostique

On distingue les atteintes de l'immunité humorale, cellulaire et les altérations de la phagocytose qui exposent à des profils d'agents infectieux différents

Il est fréquent que les patients cumulent plusieurs types d'immunosuppression

L'atteinte de l'immunité humorale expose avant tout à des germes encapsulés

L'atteinte de l'immunité cellulaire expose avant tout à des infections opportunistes

En cas d'altération de la phagocytose, le risque pyogène est constant, et le risque fongique varie selon la durée et la profondeur de la neutropénie

Au cours de la greffe hématopoḯtique et de la greffe d'organe solide, le risque infectieux varie avec le délai depuis la greffe, la durée du traitement immunosuppresseur et les prophylaxies prises par le patient

Sous prophylaxie bien conduite, le risque de pneumocystose est virtuel. On note une augmentation du risque d'infection à champignons émergents (Mucorales en particulier), dont le diagnostic pourrait être amélioré avec l'avènement des techniques de biologie moléculaire

formulation intraveineuse est souvent nécessaire chez les patients de réanimation, avec des objectifs de concentration sériques de 2-4 mg/l [82], en prenant en compte le risque de toxicité hépatique et les interactions avec les IS. La dose d'anticalcineurines doit souvent être réduite, et la coadministration de sirolimus est habituellement contreindiquée [83]. Si le diagnostic de mucormysose est confirmé, l'amphotéricine $\mathrm{B}$ à forte dose $(>5 \mathrm{mg} / \mathrm{kg}$ par jour) sera privilégiée [44]. Le traitement de la cryptococcose repose sur l'amphotéricine B liposomale ( $3 \mathrm{mg} / \mathrm{kg}$ par jour) associée à la flucytosine (25 $\mathrm{mg} / \mathrm{kg}$ par six heures) [82]. En cas d'atteinte pulmonaire focale peu symptomatique, le fluconazole à $6 \mathrm{mg} / \mathrm{kg}$ par jour pendant 6-12 mois peut être suffisant [82]. 
Enfin, les formes sévères de tuberculose doivent être traitées par quadrithérapies comportant de la rifampicine malgré le risque d'interaction important avec les IS (anticalcineurine, inhibiteur de mTOR, dont les doses doivent être augmentées de trois à cinq fois, corticoïdes dont la posologie doit être doublée) [134].

\section{Conclusion}

Les complications infectieuses respiratoires représentent la première cause d'admission en réanimation chez les patients immunodéprimés. La mortalité est élevée, notamment en l'absence de diagnostic étiologique. La démarche diagnostique doit être rigoureuse, guidée par le type d'immunodépression et le tableau clinique.

Liens d'intérêts : les auteurs ne déclarent aucun conflit d'intérêt en lien avec le sujet traité.

\section{Références}

1. Harpaz R, Dahl RM, Dooling KL, (2016) Prevalence of immunosuppression among US Adults, 2013. JAMA 316: 2547-2548. doi: 10.1001/jama.2016.16477

2. Jemal A, Ward EM, Johnson CJ, Cronin KA, Ma J, Ryerson B, Mariotto A, Lake AJ, Wilson R, Sherman RL, Anderson RN, Henley SJ, Kohler BA, Penberthy L, Feuer EJ, Weir HK, (2017) Annual Report to the Nation on the Status of Cancer, 1975-2014, Featuring Survival. J Natl Cancer Inst 109. doi: 10.1093/jnci/djx030

3. Canet E, Zafrani L, Azoulay E, (2016) The critically ill kidney transplant recipient: a narrative review. Chest 149: 1546-1555. doi: 10.1016/j.chest.2016.01.002

4. Dumas G, Géri G, Montlahuc C, Chemam S, Dangers L, Pichereau C, Brechot N, Duprey M, Mayaux J, Schenck M, BoisraméHelms J, Thomas G, Baboi L, Mouthon L, Amoura Z, Papo T, Mahr A, Chevret S, Chiche JD, Azoulay E, (2015) Outcomes in critically ill patients with systemic rheumatic disease: a multicenter study. Chest 148: 927-935. doi: 10.1378/chest.14-3098

5. Azoulay E, Mokart D, Pène F, Lambert J, Kouatchet A, Mayaux J, Vincent F, Nyunga M, Bruneel F, Laisne LM, Rabbat A, Lebert C, Perez P, Chaize M, Renault A, Meert AP, Benoit D, Hamidfar R, Jourdain M, Darmon M, Schlemmer B, Chevret S, Lemiale V, (2013) Outcomes of critically ill patients with hematologic malignancies: prospective multicenter data from France and Belgium: a groupe de recherche respiratoire en réanimation onco-hématologique study. J Clin Oncol 31: 2810-2818. doi: 10.1200/JCO.2012.47.2365

6. Azoulay E, Pickkers P, Soares M, Perner A, Rello J, Bauer PR, van de Louw A, Hemelaar P, Lemiale V, Taccone FS, Martin Loeches I, Meyhoff TS, Salluh J, Schellongowski P, Rusinova K, Terzi N, Mehta S, Antonelli M, Kouatchet A, Barratt-Due A, Valkonen M, Landburg PP, Bruneel F, Bukan RB, Pène F, Metaxa V, Moreau AS, Souppart V, Burghi G, Girault C, Silva UVA, Montini L, Barbier F, Nielsen LB, Gaborit B, Mokart D, Chevret S, Efraim investigators and the Nine-I study group, (2017) Acute hypoxemic respiratory failure in immunocompromised patients: the Efraim multinational prospective cohort study. Intensive Care Med 43: 1808-1819. doi: 10.1007/s00134-017-4947-1
7. Contejean A, Lemiale V, Resche-Rigon M, Mokart D, Pène F, Kouatchet A, Mayaux J, Vincent F, Nyunga M, Bruneel F, Rabbat A, Perez P, Meert AP, Benoit D, Hamidfar R, Darmon M, Jourdain M, Renault A, Schlemmer B, Azoulay E, (2016) Increased mortality in hematological malignancy patients with acute respiratory failure from undetermined etiology: a Groupe de Recherche en Réanimation Respiratoire en Onco-Hématologique (Grrr-OH) study. Ann Intensive Care 6: 102. doi: 10.1186/s13613-016-0202-0

8. Schnell D, Mayaux J, Lambert J, Roux A, Moreau AS, Zafrani L, Canet E, Lemiale V, Darmon M, Azoulay E, (2013) Clinical assessment for identifying causes of acute respiratory failure in cancer patients. Eur Respir J 42: 435-443. doi: 10.1183/09031936.00122512

9. Novosad SA, Winthrop KL, (2014) Beyond tumor necrosis factor inhibition: the expanding pipeline of biologic therapies for inflammatory diseases and their associated infectious sequelae. Clin Infect Dis 58: 1587-1598. doi: 10.1093/cid/ciu104

10. Salvana EMT, Salata RA, (2009) Infectious complications associated with monoclonal antibodies and related small molecules. Clin Microbiol Rev 22: 274-290, Table of Contents. doi: 10.1128/CMR.00040-08

11. Janeway CA Jr, Travers P, Walport M, Shlomchik MJ, (2001) Immunobiology, 5th ed. Garland Science

12. Morrison VA, (2014) Immunosuppression associated with novel chemotherapy agents and monoclonal antibodies. Clin Infect Dis 59: S360-S364. doi: 10.1093/cid/ciu592

13. Carroll MC, Holers VM, (2005) Innate autoimmunity. Adv Immunol 86: 137-157. doi: 10.1016/S0065-2776(04)86004-8

14. Picard C, Al-Herz W, Bousfiha A, Casanova JL, Chatila T, Conley ME, Cunningham-Rundles C, Etzioni A, Holland SM, Klein C, Nonoyama S, Ochs HD, Oksenhendler E, Puck JM, Sullivan KE, Tang ML, Franco JL, Gaspar HB, (2015) Primary immunodeficiency diseases: an update on the classification from the International Union of Immunological Societies Expert Committee for Primary Immunodeficiency 2015. J Clin Immunol 35: 696-726. doi: 10.1007/s10875-015-0201-1

15. Medzhitov R, (2007) Recognition of microorganisms and activation of the immune response. Nature 449: 819-826. doi: 10.1038 /nature 06246

16. Fleer A, (2000) Cellular and humoral defence mechanisms against bacteria. Paediatr Respir Rev 1: 235-240. doi: 10.1053/prrv.2000.0054

17. Wehr C, Kivioja T, Schmitt C, Ferry B, Witte T, Eren E, Vlkova M, Hernandez M, Detkova D, Bos PR, Poerksen G, von Bernuth H, Baumann U, Goldacker S, Gutenberger S, Schlesier M, Bergeronvan der Cruyssen F, Le Garff M, Debré P, Jacobs R, Jones J, Bateman E, Litzman J, van Hagen PM, Plebani A, Schmidt RE, Thon V, Quinti I, Espanol T, Webster AD, Chapel H, Vihinen M, Oksenhendler E, Peter HH, Warnatz K, (2008) The EUROclass trial: defining subgroups in common variable immunodeficiency. Blood 111: 77-85. doi: 10.1182/blood-2007-06-091744

18. Azar AE, Ballas ZK, (2007) Evaluation of the adult with suspected immunodeficiency. Am J Med 120: 764-768. doi: 10.1016/j.amjmed.2006.12.013

19. Casulo C, Maragulia J, Zelenetz AD, (2013) Incidence of hypogammaglobulinemia in patients receiving rituximab and the use of intravenous immunoglobulin for recurrent infections. Clin Lymphoma Myeloma Leuk 13: 106-111. doi: 10.1016/j.clml.2012.11.011

20. Gottenberg JE, Ravaud P, Bardin T, Cacoub P, Cantagrel A, Combe B, Dougados M, Flipo RM, Godeau B, Guillevin L, Le Loët X, Hachulla E, Schaeverbeke T, Sibilia J, Baron G, Mariette $\mathrm{X}$; AutoImmunity and Rituximab registry and French Society of Rheumatology, (2010) Risk factors for severe infections in patients with rheumatoid arthritis treated with rituximab in the autoimmunity and rituximab registry. Arthritis Rheum 62: 2625-2632. doi: 10.1002/art.27555 
21. Arai Y, Yamashita K, Mizugishi K, Kondo T, Kitano T, Hishizawa M, Kadowaki N, Takaori-Kondo A, (2014) Risk factors for hypogammaglobulinemia after allo-SCT. Bone Marrow Transplant 49: 859-861. doi: 10.1038/bmt.2014.28

22. Oksenhendler E, Gérard L, Fieschi C, Malphettes M, Mouillot G, Jaussaud R, Viallard JF, Gardembas M, Galicier L, Schleinitz N, Suarez F, Soulas-Sprauel P, Hachulla E, Jaccard A, Gardeur A, Théodorou I, Rabian C, Debré P; DEFI Study Group, (2008) Infections in 252 patients with common variable immunodeficiency. Clin Infect Dis 46: 1547-1554. doi: 10.1086/587669

23. Polverino E, Goeminne PC, McDonnell MJ, Aliberti S, Marshall SE, Loebinger MR, Murris M, Cantón R, Torres A, Dimakou K, De Soyza A, Hill AT, Haworth CS, Vendrell M, Ringshausen FC, Subotic D, Wilson R, Vilaró J, Stallberg B, Welte T, Rohde G, Blasi F, Elborn S, Almagro M, Timothy A, Ruddy T, Tonia T, Rigau D, Chalmers JD, (2017) European Respiratory Society guidelines for the management of adult bronchiectasis. Eur Respir J 50. pii: 1700629. doi: 10.1183/13993003.00629-2017

24. Tarr PE, Sneller MC, Mechanic LJ, Economides A, Eger CM, Strober W, Cunningham-Rundles C, Lucey DR, (2001) Infections in patients with immunodeficiency with thymoma (Good syndrome). Report of 5 cases and review of the literature. Medicine (Baltimore) 80: 123-133

25. Compagno N, Malipiero G, Cinetto F, Agostini C, (2014) Immunoglobulin Replacement Therapy in Secondary Hypogammaglobulinemia. Front Immunol 5: 626. doi: 10.3389/fimmu.2014.00626

26. Ricklin D, Hajishengallis G, Yang K, Lambris JD, (2010) Complement: a key system for immune surveillance and homeostasis. Nat Immunol 11: 785-797. doi: 10.1038/ni.1923

27. Turley AJ, Gathmann B, Bangs C, Bradbury M, Seneviratne S, Gonzalez-Granado LI, Hackett S, Kutukculer N, Alachkar H, Hambleton S, Ritterbusch H, Kralickova P, Marodi L, Seidel MG, Dueckers G, Roesler J, Huissoon A, Baxendale H, Litzman J, Arkwright PD, (2015) Spectrum and management of complement immunodeficiencies (excluding hereditary angioedema) across Europe. J Clin Immunol 35: 199-205. doi: 10.1007/s10875-015-0137-5

28. Audemard-Verger A, Descloux E, Ponard D, Deroux A, Fantin B, Fieschi C, John M, Bouldouyre A, Karkowsi L, Moulis G, Auvinet $\mathrm{H}$, Valla F, Lechiche C, Davido B, Martinot M, Biron C, Lucht F, Asseray N, Froissart A, Buzelé R, Perlat A, Boutboul D, Fremeaux-Bacchi V, Isnard S, Bienvenu B, (2016) Infections revealing complement deficiency in adults. Medicine (Baltimore) 95: e3548. doi: 10.1097/MD.0000000000003548

29. Benamu E, Montoya JG, (2016) Infections associated with the use of eculizumab: recommendations for prevention and prophylaxis. Curr Opin Infect Dis 29: 319-329. doi: 10.1097/ QCO.0000000000000279

30. Di Sabatino A, Carsetti R, Corazza GR, (2011) Post-splenectomy and hyposplenic states. Lancet Lond Engl 378: 86-97. doi: 10.1016/S0140-6736(10)61493-6

31. Weller S, Braun MC, Tan BK, Rosenwald A, Cordier C, Conley ME, Plebani A, Kumararatne DS, Bonnet D, Tournilhac O, Tchernia G, Steiniger B, Staudt LM, Casanova JL, Reynaud CA, Weill JC, (2004) Human blood IgM "memory" B cells are circulating splenic marginal zone B cells harboring a prediversified immunoglobulin repertoire. Blood 104: 3647-3654. doi: 10.1182/blood-2004-01-0346

32. O'Neal HR, Niven AS, Karam GH, (2016) Critical Illness in Patients With Asplenia. Chest 150: 1394-1402. doi: 10.1016/j.chest.2016.03.044

33. Robinette CD, Fraumeni JF, (1977) Splenectomy and subsequent mortality in veterans of the 1939-45 war. Lancet Lond Engl 2: $127-129$
34. Fair KA, Connelly CR, Hart KD, Schreiber MA, Watters JM, (2017) Splenectomy is associated with higher infection and pneumonia rates among trauma laparotomy patients. Am J Surg 213: 856-861. doi: 10.1016/j.amjsurg.2017.04.001

35. Theilacker C, Ludewig K, Serr A, Schimpf J, Held J, Bögelein M, Bahr V, Rusch S, Pohl A, Kogelmann K, Frieseke S, Bogdanski R, Brunkhorst FM, Kern WV, (2016) Overwhelming Postsplenectomy Infection: A Prospective Multicenter Cohort Study. Clin Infect Dis 62: 871-878. doi: 10.1093/cid/civ1195

36. Bhavsar AP, Guttman JA, Finlay BB, (2007) Manipulation of hostcell pathways by bacterial pathogens. Nature 449: 827-834. doi: 10.1038 /nature06247

37. Weiss G, Schaible UE, (2015) Macrophage defense mechanisms against intracellular bacteria. Immunol Rev 264: 182-203. doi: 10.1111/imr.12266

38. Berliner N, Horwitz M, Loughran TP, (2004) Congenital and acquired neutropenia. Hematol Am Soc Hematol Educ Program 2004: 63-79. doi: 10.1182/asheducation-2004.1.63

39. de Naurois J, Novitzky-Basso I, Gill MJ, Marti FM, Cullen MH, Roila F; ESMO Guidelines Working Group, (2010) Management of febrile neutropenia: ESMO Clinical Practice Guidelines. Ann Oncol 21: v252-v256. doi: 10.1093/annonc/mdq196

40. Freifeld AG, Bow EJ, Sepkowitz KA, Boeckh MJ, Ito JI, Mullen CA, Raad II, Rolston KV, Young JA, Wingard JR; Infectious Diseases Society of America, (2011) Clinical practice guideline for the use of antimicrobial agents in neutropenic patients with cancer: 2010 update by the infectious diseases society of america. Clin Infect Dis 52: e56-e93. doi: 10.1093/cid/cir073

41. Evans SE, Ost DE, (2015) Pneumonia in the neutropenic cancer patient. Curr Opin Pulm Med 21:260-271. doi: 10.1097/ MCP.0000000000000156

42. Vento S, Cainelli F, Temesgen Z, (2008) Lung infections after cancer chemotherapy. Lancet Oncol 9:982-992. doi: 10.1016/ S1470-2045(08)70255-9

43. Subirà M, Martino R, Franquet T, Puzo C, Altés A, Sureda A, Brunet S, Sierra J, (2002) Invasive pulmonary aspergillosis in patients with hematologic malignancies: survival and prognostic factors. Haematologica 87: 528-534

44. Cornely OA, Arikan $\square$ Akdagli S, Dannaoui E, Groll AH. Lagrou K, Chakrabarti A, Lanternier F, Pagano L, Skiada A, Akova M, Arendrup MC, Boekhout T, Chowdhary A, Cuenca $\square$ Estrella M, Freiberger T, Guinea J, Guarro J, de Hoog S, Hope W, Johnson E, Kathuria S, Lackner M, Lass $\square$ Flörl C, Lortholary O, Meis JF, Meletiadis J, Muñoz P, Richardson M, Roilides E, Tortorano AM, Ullmann AJ, van Diepeningen A, Verweij P, Petrikkos G, (2014) ESCMID and ECMM joint clinical guidelines for the diagnosis and management of mucormycosis 2013. Clin Microbiol Infect 20: 5-26. doi: 10.1111/1469-0691.12371

45. Patterson TF, Thompson GR, Denning DW, Fishman JA, Hadley S, Herbrecht R, Kontoyiannis DP, Marr KA, Morrison VA, Nguyen MH, Segal BH, Steinbach WJ, Stevens DA, Walsh TJ, Wingard JR, Young JA, Bennett JE, (2016) Executive Summary: Practice Guidelines for the Diagnosis and Management of Aspergillosis: 2016 Update by the Infectious Diseases Society of America. Clin Infect Dis 63: 433-442. doi: 10.1093/cid/ciw444

46. Wingard JR, Hiemenz JW, Jantz MA, (2012) How I manage pulmonary nodular lesions and nodular infiltrates in patients with hematologic malignancies or undergoing hematopoietic cell transplantation. Blood 120: 1791-1800. doi: 10.1182/ blood-2012-02-378976

47. Milito MA, Kontoyiannis DP, Lewis RE, Liu P, Mawlawi OR, Truong MT, Marom EM, (2010) Influence of host immunosuppression on $\mathrm{CT}$ findings in invasive pulmonary aspergillosis. Med Mycol 48: 817-823. doi: 10.3109/13693780903514872 
48. Greene RE, Schlamm HT, Oestmann JW, Stark P, Durand C, Lortholary O, Wingard JR, Herbrecht R, Ribaud P, Patterson TF, Troke PF, Denning DW, Bennett JE, de Pauw BE, Rubin RH, (2007) Imaging findings in acute invasive pulmonary aspergillosis: clinical significance of the halo sign. Clin Infect Dis 44: 373379. doi: $10.1086 / 509917$

49. Bergeron A, Porcher R, Sulahian A, de Bazelaire C, Chagnon K, Raffoux E, Vekhoff A, Cornet M, Isnard F, Brethon B, Lacroix C, Poirot JL, Bouges C, Derouin F, Tazi A, Ribaud P, (2012) The strategy for the diagnosis of invasive pulmonary aspergillosis should depend on both the underlying condition and the leukocyte count of patients with hematologic malignancies. Blood 119: 1831-1837; quiz 1956. doi: 10.1182/blood-2011-04-351601

50. Rolston KVI, Bodey GP, Safdar A, (2007) Polymicrobial infection in patients with cancer: an underappreciated and underreported entity. Clin Infect Dis Off Publ Infect Dis Soc Am 45:228233. doi: $10.1086 / 518873$

51. Chamilos G, Marom EM, Lewis RE, Lionakis MS, Kontoyiannis DP, (2005) Predictors of pulmonary zygomycosis versus invasive pulmonary aspergillosis in patients with cancer. Clin Infect Dis 41: 60-66. doi: 10.1086/430710

52. Reichenberger F, Habicht JM, Gratwohl A, Tamm M, (2002) Diagnosis and treatment of invasive pulmonary aspergillosis in neutropenic patients. Eur Respir J 19: 743-755

53. Nucci M, Anaissie E, (2007) Fusarium infections in immunocompromised patients. Clin Microbiol Rev 20: 695-704. doi: 10.1128/CMR.00014-07

54. Lekstrom-Himes JA, Gallin JI, (2000) Immunodeficiency diseases caused by defects in phagocytes. N Engl J Med 343: 17031714. doi: 10.1056/NEJM200012073432307

55. Grever MR, Abdel-Wahab O, Andritsos LA, Banerji V, Barrientos J, Blachly JS, Call TG, Catovsky D, Dearden C, Demeter J, Else M, Forconi F, Gozzetti A, Ho AD, Johnston JB, Jones J, Juliusson G, Kraut E, Kreitman RJ, Larratt L, Lauria F, Lozanski G, Montserrat E, Parikh SA, Park JH, Polliack A, Quest GR, Rai KR, Ravandi F, Robak T, Saven A, Seymour JF, Tadmor T, Tallman MS, Tam C, Tiacci E, Troussard X, Zent CS, Zenz T, Zinzani PL, Falini B, (2017) Consensus guidelines for the diagnosis and management of patients with classic hairy cell leukemia. Blood 129: 553-560. doi: 10.1182/blood-2016-01-689422

56. Ahmed S, Siddiqui AK, Rossoff L, Sison CP, Rai KR, (2003) Pulmonary complications in chronic lymphocytic leukemia. Cancer 98: 1912-1917. doi: 10.1002/cncr.11736

57. Tomblyn M, Chiller T, Einsele H, Gress R, Sepkowitz K, Storek J, Wingard JR, Young JA, Boeckh MJ, Center for International Blood and Marrow Research, National Marrow Donor program, European Blood and MarrowTransplant Group, American Society of Blood and Marrow Transplantation, Canadian Blood and Marrow Transplant Group, Infectious Diseases Society of America, Society for Healthcare Epidemiology of America, Association of Medical Microbiology and Infectious Disease Canada, Centers for Disease Control and Prevention, (2009) Guidelines for preventing infectious complications among hematopoietic cell transplantation recipients: a global perspective. Biol Blood Marrow Transplant 15: 1143-1238. doi: 10.1016/ j.bbmt.2009.06.019

58. Dettenkofer M, Wenzler-Röttele S, Babikir R, Bertz H, Ebner W, Meyer E, Rüden H, Gastmeier P, Daschner FD, Hospital Infection Surveillance System for Patients with Hematologic/Oncologic Malignancies Study Group, (2005) Surveillance of nosocomial sepsis and pneumonia in patients with a bone marrow or peripheral blood stem cell transplant: a multicenter project. Clin Infect Dis 40: 926-931. doi: 10.1086/428046

59. Gil L, Kozlowska-Skrzypczak M, Mol A, Poplawski D, Styczynski J, Komarnicki M, (2009) Increased risk for invasive aspergillosis in patients with lymphoproliferative diseases after autolo- gous hematopoietic SCT. Bone Marrow Transplant 43: 121-126. doi: 10.1038/bmt.2008.303

60. Miller HK, Braun TM, Stillwell T, Harris AC, Choi S, Connelly J, Couriel D, Goldstein S, Kitko CL, Magenau J, Pawarode A, Reddy P, Riwes M, Yanik GA, Levine JE, (2017) Infectious risk after allogeneic hematopoietic cell transplantation complicated by acute graft-versus-host disease. Biol Blood Marrow Transplant 23: 522-528. doi: 10.1016/j.bbmt.2016.12.630

61. Matsumura-Kimoto Y, Inamoto Y, Tajima K, Kawajiri A, Tanaka T, Hirakawa T, Ino K, Asao Y, Tamogami H, Kono C, Takeda W, Okinaka K, Fuji S, Kurosawa S, Kim SW, Tanosaki R, Yamashita T, Fukuda T, (2016) Association of cumulative steroid dose with risk of infection after treatment for severe acute graft-versus-host disease. Biol Blood Marrow Transplant 22: 1102-1107. doi: 10.1016/j.bbmt.2016.02.020

62. Emery V, Zuckerman M, Jackson G, Aitken C, Osman H, Pagliuca A, Potter M, Peggs K, Clark A; British Committee for Standards in Haematology, British Society of Blood and Marrow Transplantation, UK Virology Network, (2013) Management of cytomegalovirus infection in haemopoietic stem cell transplantation. Br J Haematol 162: 25-39. doi: 10.1111/bjh.12363

63. Williams KM, Ahn KW, Chen M, Aljurf MD, Agwu AL, Chen AR, Walsh TJ, Szabolcs P, Boeckh MJ, Auletta JJ, Lindemans CA, Zanis-Neto J, Malvezzi M, Lister J, de Toledo Codina JS, Sackey K, Chakrabarty JL, Ljungman P, Wingard JR, Seftel MD, Seo S, Hale GA, Wirk B, Smith MS, Savani BN, Lazarus HM, Marks DI, Ustun C, Abdel-Azim H, Dvorak CC, Szer J, Storek J, Yong A, Riches MR, (2016) The incidence, mortality and timing of Pneumocystis jiroveci pneumonia after hematopoietic cell transplantation: a CIBMTR analysis. Bone Marrow Transplant 51: 573-580. doi: 10.1038/bmt.2015.316

64. Erard V, Guthrie KA, Seo S, Smith J, Huang M, Chien J, Flowers ME, Corey L, Boeckh M, (2015) Reduced mortality of cytomegalovirus Pneumonia after hematopoietic cell transplantation due to antiviral therapy and changes in transplantation practices. Clin Infect Dis Off Publ Infect Dis Soc Am 61: 31-39. doi: $10.1093 / \mathrm{cid} / \mathrm{civ} 215$

65. Travi G, Pergam SA, (2014) Cytomegalovirus pneumonia in hematopoietic stem cell recipients. J Intensive Care Med 29: 200-212. doi: 10.1177/0885066613476454

66. Kotton CN, (2013) CMV: Prevention, Diagnosis and Therapy. Am J Transplant Off J Am Soc Transplant Am Soc Transpl Surg 13: 24-40; quiz 40. doi: 10.1111/ajt.12006

67. Girmenia C, Ferretti A, Barberi W, (2014) Epidemiology and risk factors for invasive fungal diseases in hematopoietic stem cell transplantation. Curr Opin Hematol 21: 459-465. doi: 10.1097/MOH.0000000000000086

68. Ullmann AJ, Lipton JH, Vesole DH, Chandrasekar P, Langston A, Tarantolo SR, Greinix H, Morais de Azevedo W, Reddy V, Boparai N, Pedicone L, Patino H, Durrant S, (2007) Posaconazole or fluconazole for prophylaxis in severe graft-versus-host disease. $\mathrm{N}$ Engl J Med 356: 335-347. doi: 10.1056/NEJMoa061098

69. de la Cámara R, Martino R, Granados E, Rodriguez-Salvanés FJ, Rovira M, Cabrera R, López J, Parody R, Sierra J, FernándezRañada JM, Carreras E, (2000) Tuberculosis after hematopoietic stem cell transplantation: incidence, clinical characteristics and outcome. Spanish Group on Infectious Complications in Hematopoietic Transplantation. Bone Marrow Transplant 26: 291-298. doi: $10.1038 /$ sj.bmt. 1702506

70. Cordonnier C, Martino R, Trabasso P, Held TK, Akan H, Ward MS, Fabian K, Ullmann AJ, Wulffraat N, Ljungman P, Alessandrino EP, Pretnar J, Gmür J, Varela R, Vitek A, Sica S, Rovira M, European Blood and Marrow Transplant Group Infectious Diseases Working Party, (2004) Mycobacterial infection: a difficult and late diagnosis in stem cell transplant recipients. Clin Infect Dis 38: 1229-1236. doi: 10.1086/383307 
71. Giannella M, Muñoz P, Alarcón JM, Mularoni A, Grossi P, Bouza E, PISOT study group, (2014) Pneumonia in solid organ transplant recipients: a prospective multicenter study. Transpl Infect Dis 16: 232-241. doi: 10.1111/tid.12193

72. Villacian JS, Paya CV, (1999) Prevention of infections in solid organ transplant recipients. Transpl Infect Dis 1: 50-64

73. Florescu DF, Kalil AC, Qiu F, Schmidt CM, Sandkovsky U, (2013) What is the impact of hypogammaglobulinemia on the rate of infections and survival in solid organ transplantation? A meta-analysis. Am J Transplant 13: 2601-2610. doi: 10.1111/ajt.12401

74. Zafrani L, Truffaut L, Kreis H, Etienne D, Rafat C, Lechaton S, Anglicheau D, Zuber J, Ciroldi M, Thervet E, Snanoudj R, Mamzer MF, Martinez F, Timsit MO, Bergougnoux L, Legendre C, (2009) Incidence, risk factors and clinical consequences of neutropenia following kidney transplantation: a retrospective study. Am J Transplant 9: 1816-1825. doi: 10.1111/j.1600-6143.2009.02699.x

75. Fishman JA, (2007) Infection in solid-organ transplant recipients. N Engl J Med 357:2601-2614. doi: 10.1056/NEJMra064928

76. Kovats Z, Sütto Z, Muraközy G, Bohacs A, Czebe K, Lang G, Renyi-Vamos F, Klepetko W, Müller V, (2011) Airway pathogens during the first year after lung transplantation: a single-center experience. Transplant Proc 43: 1290-1291. doi: 10.1016/ j.transproceed.2011.03.075

77. Pappas PG, Alexander BD, Andes DR, Hadley S, Kauffman CA, Freifeld A, Anaissie EJ, Brumble LM, Herwaldt L, Ito J, Kontoyiannis DP, Lyon GM, Marr KA, Morrison VA, Park BJ, Patterson TF, Perl TM, Oster RA, Schuster MG, Walker R, Walsh TJ, Wannemuehler KA, Chiller TM, (2010) Invasive fungal infections among organ transplant recipients: results of the Transplant-Associated Infection Surveillance Network (TRANSNET). Clin Infect Dis 50: 1101-1111. doi: 10.1086/651262

78. Gavalda J, Len O, San Juan R, Aguado JM, Fortun J, Lumbreras C, Moreno A, Munoz P, Blanes M, Ramos A, Rufi G, Gurgui M, Torre-Cisneros J, Montejo M, Cuenca-Estrella M, RodriguezTudela JL, Pahissa A, RESITRA (Spanish Network for Research on Infection in Transplantation), (2005) Risk factors for invasive aspergillosis in solid-organ transplant recipients: a case-control study. Clin Infect Dis 41: 52-59. doi: 10.1086/430602

79. Fishman JA, (2017) Infection in Organ Transplantation. Am J Transplant 17: 856-879. doi: 10.1111/ajt.14208

80. Fillatre P, Decaux O, Jouneau S, Revest M, Gacouin A, RobertGangneux F, Fresnel A, Guiguen C, Le Tulzo Y, Jégo P, Tattevin $\mathrm{P}$, (2014) Incidence of Pneumocystis jiroveci Pneumonia among Groups at Risk in HIV-negative Patients. Am J Med 127: 1242.e11-1242.e17. doi: 10.1016/j.amjmed.2014.07.010

81. Bige N, Zafrani L, Lambert J, Peraldi MN, Snanoudj R, Reuter D, Legendre C, Chevret S, Lemiale V, Schlemmer B, Azoulay E, Canet E, (2014) Severe infections requiring intensive care unit admission in kidney transplant recipients: impact on graft outcome. Transpl Infect Dis 16: 588-596. doi: 10.1111/tid.12249

82. Gavaldà J, Meije Y, Fortún J, Roilides E, Saliba F, Lortholary O, Muñoz P, Grossi P, Cuenca-Estrella M, ESCMID Study Group for Infections in Compromised Hosts, (2014) Invasive fungal infections in solid organ transplant recipients. Clin Microbiol Infect 20: 27-48. doi: 10.1111/1469-0691.12660

83. Grossi P, Farina C, Fiocchi R, Dalla Gasperina D, (2000) Prevalence and outcome of invasive fungal infections in 1,963 thoracic organ transplant recipients: a multicenter retrospective study. Italian Study Group of Fungal Infections in Thoracic Organ Transplant Recipients. Transplantation 70: 112-116

84. Singh N, Aguado JM, Bonatti H, Forrest G, Gupta KL, Safdar N, John GT, Pursell KJ, Muñoz P, Patel R, Fortun J, Martin-Davila P, Philippe B, Philit F, Tabah A, Terzi N, Chatelet V, Kusne S, Clark N, Blumberg E, Julia MB, Humar A, Houston S, Lass-Flörl C, Johnson L, Dubberke ER, Barron MA, Lortholary O, (2009) Zygomycosis in solid organ transplant recipients: a prospective, matched case-control study to assess risks for disease and outcome. J Infect Dis 200: 1002-1011. doi: 10.1086/605445

85. Miller R, Assi M, AST Infectious Diseases Community of Practice, (2013) Endemic fungal infections in solid organ transplantation. Am J Transplant Off J Am Soc Transplant Am Soc Transpl Surg 13 Suppl 4: 250-261. doi: 10.1111/ajt.12117

86. Torre-Cisneros J, Doblas A, Aguado JM, San Juan R, Blanes M, Montejo M, Cervera C, Len O, Carratala J, Cisneros JM, Bou G, Muñoz P, Ramos A, Gurgui M, Borrell N, Fortún J, Moreno A, Gavalda J, Spanish Network for Research in Infectious Diseases, (2009) Tuberculosis after solid-organ transplant: incidence, risk factors, and clinical characteristics in the RESITRA (Spanish Network of Infection in Transplantation) cohort. Clin Infect Dis 48: 1657-1665. doi: 10.1086/599035

87. George IA, Santos CAQ, Olsen MA, Bailey TC, (2016) Epidemiology and Outcomes of Nontuberculous Mycobacterial Infections in Solid Organ Transplant Recipients at a Midwestern Center. Transplantation 100: 1073-1078. doi: 10.1097/TP.0000000000001123

88. Griffith DE, Aksamit T, Brown-Elliott BA, Catanzaro A, Daley C, Gordin F, Holland SM, Horsburgh R, Huitt G, Iademarco MF, Iseman M, Olivier K, Ruoss S, von Reyn CF, Wallace RJ Jr, Winthrop K, ATS Mycobacterial Diseases Subcommittee, American Thoracic Society, Infectious Disease Society of America, (2007) An official ATS/IDSA statement: diagnosis, treatment, and prevention of nontuberculous mycobacterial diseases. Am J Respir Crit Care Med 175: 367-416. doi: 10.1164/rccm.200604-571ST

89. Lebeaux D, Freund R, van Delden C, Guillot H, Marbus SD, Matignon M, Van Wijngaerden E, Douvry B, De Greef J, Vuotto F, Tricot L, Fernández-Ruiz M, Dantal J, Hirzel C, Jais JP, Rodriguez-Nava V, Jacobs F, Lortholary O, Coussement J, European Study Group for Nocardia in Solid Organ Transplantation, European Study Group for Nocardia in Solid Organ Transplantation, (2017) Outcome and Treatment of Nocardiosis After Solid Organ Transplantation: New Insights From a European Study. Clin Infect Dis Off Publ Infect Dis Soc Am 64: 1396-1405. doi: 10.1093/cid/cix124

90. Coussement J, Lebeaux D, van Delden C, Guillot H, Freund R, Marbus S, Melica G, Van Wijngaerden E, Douvry B, Van Laecke S, Vuotto F, Tricot L, Fernández-Ruiz M, Dantal J, Hirzel C, Jais JP, Rodriguez-Nava V, Lortholary O, Jacobs F, European Study Group for Nocardia in Solid Organ Transplantation, (2016) Nocardia Infection in Solid Organ Transplant Recipients: A Multicenter European Case-control Study. Clin Infect Dis Off Publ Infect Dis Soc Am 63: 338-345. doi: 10.1093/cid/ciw241

91. Rúa-Figueroa Í, López-Longo J, Galindo-Izquierdo M, Calvo-Alén J, Del Campo V, Olivé-Marqués A, Pérez-Vicente S, FernándezNebro A, Andrés M, Erausquin C, Tomero E, Horcada L, Uriarte E, Freire M, Montilla C, Sánchez-Atrio A, Santos G, Boteanu A, Díez-Álvarez E, Narváez J, Martínez-Taboada V, Silva-Fernández L, Ruiz-Lucea E, Andreu JL, Hernández-Beriain JÁ, Gantes M, Hernández-Cruz B, Pérez-Venegas J, Pecondón-Español Á, Marras C, Ibáñez-Barceló M, Bonilla G, Torrente V, Castellví I, Alegre JJ, Calvet J, Marenco JL, Raya E, Vázquez T, Quevedo V, MuñozFernández S, Rodríguez-Gómez M, Ibáñez J, Pego-Reigosa JM, (2017) Incidence, associated factors and clinical impact of severe infections in a large, multicentric cohort of patients with systemic lupus erythematosus. Semin Arthritis Rheum 47: 38-45. doi: 10.1016/j.semarthrit.2017.01.010

92. Little MA, Nightingale P, Verburgh CA, Hauser T, De Groot K, Savage C, Jayne D, Harper L, European Vasculitis Study (EUVAS) Group, (2010) Early mortality in systemic vasculitis: relative contribution of adverse events and active vasculitis. Ann Rheum Dis 69: 1036-1043. doi: 10.1136/ard.2009.109389 
93. Ben m'rad M, Gherissi D, Mouthon L, Salmon-Céron D (2009) Tuberculosis risk among patients with systemic diseases. Presse Medicale Paris Fr 1983 38: 274-290. doi: 10.1016/ j.lpm.2008.11.009

94. Stuck AE, Minder CE, Frey FJ, (1989) Risk of infectious complications in patients taking glucocorticosteroids. Rev Infect Dis 11: 954-963

95. Klein NC, Go CH, Cunha BA, (2001) Infections associated with steroid use. Infect Dis Clin North Am 15: 423-432, viii

96. Ginzler E, Diamond H, Kaplan D, Weiner M, Schlesinger M, Seleznick M, (1978) Computer analysis of factors influencing frequency of infection in systemic lupus erythematosus. Arthritis Rheum 21: $37-44$

97. Jick SS, Lieberman ES, Rahman MU, Choi HK (2006) Glucocorticoid use, other associated factors, and the risk of tuberculosis. Arthritis Rheum 55: 19-26. doi: 10.1002/art.21705

98. Roux A, Gonzalez F, Roux M, Mehrad M, Menotti J, Zahar JR, Tadros VX, Azoulay E7, Brillet PY, Vincent F, Groupe de recherche respiratoire en réanimation en onco-hématologie (Grrr-OH), (2014) Update on pulmonary Pneumocystis jirovecii infection in non-HIV patients. Med Mal Infect 44: 185-198. doi: 10.1016/j.medmal.2014.01.007

99. Lionakis MS, Kontoyiannis DP, (2003) Glucocorticoids and invasive fungal infections. Lancet Lond Engl 362: 1828-1838. doi: 10.1016/S0140-6736(03)14904-5

100. Segal BH, Sneller MC, (1997) Infectious complications of immunosuppressive therapy in patients with rheumatic diseases. Rheum Dis Clin North Am 23: 219-237

101. McLean-Tooke A, Aldridge C, Waugh S, Spickett GP, Kay L, (2009) Methotrexate, rheumatoid arthritis and infection risk: what is the evidence? Rheumatol Oxf Engl 48: 867-871. doi: 10.1093/rheumatology/kep101

102. LeMense GP, Sahn SA, (1994) Opportunistic infection during treatment with low dose methotrexate. Am J Respir Crit Care Med 150: 258-260. doi: 10.1164/ajrccm.150.1.8025760

103. Bradley JD, Brandt KD, Katz BP, (1989) Infectious complications of cyclophosphamide treatment for vasculitis. Arthritis Rheum 32: 45-53

104. Singh JA, Wells GA, Christensen R, Tanjong Ghogomu E, Maxwell L, Macdonald JK, Filippini G, Skoetz N, Francis D, Lopes LC, Guyatt GH, Schmitt J, La Mantia L, Weberschock T, Roos JF, Siebert H, Hershan S, Lunn MP, Tugwell P, Buchbinder R, (2011) Adverse effects of biologics: a network metaanalysis and Cochrane overview. Cochrane Database Syst Rev 2: CD008794. doi: 10.1002/14651858.CD008794.pub2

105. Choy EH, Panayi GS, (2001) Cytokine pathways and joint inflammation in rheumatoid arthritis. N Engl J Med 344: $907-$ 916. doi: 10.1056/NEJM200103223441207

106. Galloway JB, Hyrich KL, Mercer LK, Dixon WG, Fu B, Ustianowski AP, Watson KD, Lunt M, Symmons DP, BSRBR Control Centre Consortium, British Society for Rheumatology Biologics Register, (2011) Anti-TNF therapy is associated with an increased risk of serious infections in patients with rheumatoid arthritis especially in the first 6 months of treatment: updated results from the British Society for Rheumatology Biologics Register with special emphasis on risks in the elderly. Rheumatol Oxf Engl 50: 124-131. doi: 10.1093/rheumatology/keq242

107. Dixon WG, Watson K, Lunt M, Hyrich KL, Silman AJ, Symmons DP, British Society for Rheumatology Biologics Register, (2006) Rates of serious infection, including site-specific and bacterial intracellular infection, in rheumatoid arthritis patients receiving anti-tumor necrosis factor therapy: results from the British Society for Rheumatology Biologics Register. Arthritis Rheum 54: 2368-2376. doi: 10.1002/art.21978

108. Nyboe Andersen N, Pasternak B, Friis-Møller N, Andersson M, Jess T, (2015) Association between tumour necrosis factor- $\alpha$ inhi- bitors and risk of serious infections in people with inflammatory bowel disease: nationwide Danish cohort study. BMJ 350: h2809

109. Gómez-Reino JJ, Carmona L, Angel Descalzo M, Biobadaser Group, (2007) Risk of tuberculosis in patients treated with tumor necrosis factor antagonists due to incomplete prevention of reactivation of latent infection. Arthritis Rheum 57: 756-761. doi: 10.1002/art.22768

110. Tubach F, Salmon D, Ravaud P, Allanore Y, Goupille P, Bréban M, Pallot-Prades B, Pouplin S, Sacchi A, Chichemanian RM, Bretagne S, Emilie D, Lemann M, Lortholary O, Mariette X, Research Axed on Tolerance of Biotherapies Group, (2009) Risk of tuberculosis is higher with anti-tumor necrosis factor monoclonal antibody therapy than with soluble tumor necrosis factor receptor therapy: The three-year prospective French Research Axed on Tolerance of Biotherapies registry. Arthritis Rheum 60: 1884-1894. doi: 10.1002/art.24632

111. Lanternier F, Tubach F, Ravaud P, Salmon D, Dellamonica P, Bretagne S, Couret M, Bouvard B, Debandt M, Gueit I, Gendre JP, Leone J, Nicolas N, Che D, Mariette X, Lortholary O, Research Axed on Tolerance of Biotherapies Group, (2013) Incidence and risk factors of Legionella pneumophila pneumonia during anti-tumor necrosis factor therapy: a prospective French study. Chest 144: 990-998. doi: 10.1378/chest.12-2820

112. Wallis RS, Broder M, Wong J, Lee A, Hoq L, (2005) Reactivation of latent granulomatous infections by infliximab. Clin Infect Dis 41: S194-S198. doi: 10.1086/429996

113. Tsiodras S, Samonis G, Boumpas DT, Kontoyiannis DP, (2008) Fungal infections complicating tumor necrosis factor alpha blockade therapy. Mayo Clin Proc 83: 181-194

114. Terrier B, Amoura Z, Ravaud P, Hachulla E, Jouenne R, Combe B, Bonnet C, Cacoub P, Cantagrel A, de Bandt M, Fain O, Fautrel B, Gaudin P, Godeau B, Harlé JR, Hot A, Kahn JE, Lambotte O, Larroche C, Léone J, Meyer O, Pallot-Prades B, Pertuiset E, Quartier P, Schaerverbeke T, Sibilia J, Somogyi A, Soubrier M, Vignon E, Bader-Meunier B, Mariette X, Gottenberg JE, Club Rhumatismes et Inflammation, (2010) Safety and efficacy of rituximab in systemic lupus erythematosus: results from 136 patients from the French AutoImmunity and Rituximab registry. Arthritis Rheum 62: 2458-2466. doi: 10.1002/art.27541

115. Jiang X, Mei X, Feng D, Wang X, (2015) Prophylaxis and Treatment of Pneumocystis jiroveci Pneumonia in Lymphoma Patients Subjected to Rituximab-Contained Therapy: A Systemic Review and Meta-Analysis. PloS One 10: e0122171. doi: 10.1371/journal.pone.0122171

116. Kelesidis T, Daikos G, Boumpas D, Tsiodras S, (2011) Does rituximab increase the incidence of infectious complications? A narrative review. Int $\mathrm{J}$ Infect Dis 15: e2-e16. doi: 10.1016/j.ijid.2010.03.025

117. van Vollenhoven RF, Emery P, Bingham CO 3rd, Keystone EC, Fleischmann RM, Furst DE, Tyson N, Collinson N, Lehane PB, (2013) Long-term safety of rituximab in rheumatoid arthritis: 9.5-year follow-up of the global clinical trial programme with a focus on adverse events of interest in RA patients. Ann Rheum Dis 72: 1496-1502. doi: 10.1136/annrheumdis-2012-201956

118. Maertens J, Cesaro S, Maschmeyer G, Einsele H, Donnelly JP, Alanio A, Hauser PM, Lagrou K, Melchers WJ, Helweg-Larsen J, Matos O, Bretagne S, Cordonnier C, 5th European Conference on Infections in Leukaemia (ECIL-5), a joint venture of the European Group for Blood and Marrow Transplantation (EBMT), the European Organisation for Research and Treatment of Cancer (EORTC), the Immunocompromised Host Society (ICHS) and the European LeukemiaNet (ELN), (2016) ECIL guidelines for preventing Pneumocystis jirovecii pneumonia in patients with haematological malignancies and stem cell 
transplant recipients. J Antimicrob Chemother 71: 2397-2404. doi: $10.1093 / \mathrm{jac} / \mathrm{dkw} 157$

119. Martin-Garrido I, Carmona EM, Specks U, Limper AH, (2013) Pneumocystis pneumonia in patients treated with rituximab. Chest 144: 258-265. doi: 10.1378/chest.12-0477

120. Martin SI, Marty FM, Fiumara K, Treon SP, Gribben JG, Baden LR, (2006) Infectious complications associated with alemtuzumab use for lymphoproliferative disorders. Clin Infect Dis Off Publ Infect Dis Soc Am 43: 16-24. doi: 10.1086/504811

121. Peleg AY, Husain S, Kwak EJ, Silveira FP, Ndirangu M, Tran J, Shutt KA, Shapiro R, Thai N, Abu-Elmagd K, McCurry KR, Marcos A, Paterson DL, (2007) Opportunistic infections in 547 organ transplant recipients receiving alemtuzumab, a humanized monoclonal CD-52 antibody. Clin Infect Dis 44: 204-212. doi: $10.1086 / 510388$

122. Sanghavi SK, Bullotta A, Husain S, Rinaldo CR, (2012) Clinical evaluation of multiplex real-time PCR panels for rapid detection of respiratory viral infections. J Med Virol 84: 162 169. doi: $10.1002 / \mathrm{jmv} .22186$

123. Hirsch HH, Martino R, Ward KN, Boeckh M, Einsele H, Ljungman P, (2013) Fourth European Conference on Infections in Leukaemia (ECIL-4): guidelines for diagnosis and treatment of human respiratory syncytial virus, parainfluenza virus, metapneumovirus, rhinovirus, and coronavirus. Clin Infect Dis Off Publ Infect Dis Soc Am 56: 258-266. doi: 10.1093/cid/cis844

124. Dignan FL, Clark A, Aitken C, Gilleece M, Jayakar V, Krishnamurthy P, Pagliuca A, Potter MN, Shaw B, Skinner R, Turner A, Wynn RF, Coyle P, Haemato-oncology Task Force of the British Committee for Standards in Haematology, British Society for Blood and Marrow Transplantation and the UK Clinical Virology Network, (2016) BCSH/BSBMT/UK clinical virology network guideline: diagnosis and management of common respiratory viral infections in patients undergoing treatment for haematological malignancies or stem cell transplantation. $\mathrm{Br}$ J Haematol 173: 380-393. doi: 10.1111/bjh.14027

125. Schnell D, Mayaux J, de Bazelaire C, Legoff J, Feuillet S, Scieux C, Andreu-Gallien J, Darmon M, Baruchel A, Schlemmer B, Azoulay E, (2010) Risk factors for pneumonia in immunocompromised patients with influenza. Respir Med 104: 1050 1056. doi: 10.1016/j.rmed.2010.01.021

126. Manuel O, López-Medrano F, Keiser L, Welte T, Carratalà J, Cordero E, Hirsch HH, ESCMID Study Group of Infection in Compromised Hosts (ESGICH), (2014) Influenza and other respiratory virus infections in solid organ transplant recipients. Clin Microbiol Infect Off Publ Eur Soc Clin Microbiol Infect Dis 20: 102-108
127. Cordero E, Pérez-Romero P, Moreno A, Len O, Montejo M, Vidal E, Martín-Dávila P, Fariñas MC, Fernández-Sabé N, Giannella M, Pachón J, Novel influenza A(H1N1) Study Group of Spanish Network for Research in Infectious Diseases (REIPI), (2012) Pandemic influenza $A(H 1 N 1)$ virus infection in solid organ transplant recipients: impact of viral and non-viral coinfection. Clin Microbiol Infect 18: 67-73. doi: 10.1111/ j.1469-0691.2011.03537.x

128. Ison MG, (2011) Antivirals and resistance: influenza virus. Curr Opin Virol 1: 563-573. doi: 10.1016/j.coviro.2011.09.002

129. Azoulay E, Schlemmer B, (2006) Diagnostic strategy in cancer patients with acute respiratory failure. Intensive Care Med 32: 808-822. doi: 10.1007/s00134-006-0129-2

130. Cooley L, Dendle C, Wolf J, Teh BW, Chen SC, Boutlis C, Thursky KA, (2014) Consensus guidelines for diagnosis, prophylaxis and management of Pneumocystis jirovecii pneumonia in patients with haematological and solid malignancies, 2014. Intern Med J 44: 1350-1363. doi: 10.1111/imj.12599

131. Azoulay E, Mokart D, Lambert J, Lemiale V, Rabbat A, Kouatchet A, Vincent F, Gruson D, Bruneel F, Epinette-Branche G, Lafabrie A, Hamidfar-Roy R, Cracco C, Renard B, Tonnelier JM, Blot F, Chevret S, Schlemmer B, (2010) Diagnostic strategy for hematology and oncology patients with acute respiratory failure: randomized controlled trial. Am J Respir Crit Care Med 182: 1038-1046. doi: 10.1164/rccm.201001-0018OC

132. Maschmeyer G, Carratalà J, Buchheidt D, Hamprecht A, Heussel CP, Kahl C, Lorenz J, Neumann S, Rieger C, Ruhnke M, Salwender H, Schmidt-Hieber M, Azoulay E, Infectious Diseases Working Party of the German Society of Hematology and Medical Oncology, (2015) Diagnosis and antimicrobial therapy of lung infiltrates in febrile neutropenic patients (allogeneic SCT excluded): updated guidelines of the Infectious Diseases Working Party (AGIHO) of the German Society of Hematology and Medical Oncology (DGHO). Ann Oncol 26: 21-33. doi: 10.1093/annonc/mdu192

133. Leroy O, Mira JP, Montravers P, Gangneux JP, Lortholary O, AmarCand Study Group, (2010) Comparison of albicans vs. non-albicans candidemia in French intensive care units. Crit Care Lond Engl 14: R98. doi: 10.1186/cc9033

134. Meije Y, Piersimoni C, Torre-Cisneros J, Dilektasli AG, Aguado JM, ESCMID Study Group of Infection in Compromised Hosts, (2014) Mycobacterial infections in solid organ transplant recipients. Clin Microbiol Infect 20: 89-101. doi: 10.1111/ 1469-0691.12641 